\title{
Influence of dimethyl sulfide on the carbon cycle and biological production
}

\author{
Shanlin Wang $(\mathbb{D} \cdot$ Mathew Maltrud $\cdot$ Scott Elliott $\cdot$ Philip Cameron-Smith • \\ Alexandra Jonko
}

Received: 25 June 2017/Accepted: 7 February 2018/Published online: 27 February 2018

(C) The Author(s) 2018. This article is an open access publication

\begin{abstract}
Dimethyl sulfide (DMS) is a significant source of marine sulfate aerosol and plays an important role in modifying cloud properties. Fully coupled climate simulations using dynamic marine ecosystem and DMS calculations are conducted to estimate DMS fluxes under various climate scenarios and to examine the sign and strength of phytoplankton-DMS-climate feedbacks for the first time. Simulation results show small differences in the DMS production and emissions between pre-industrial and present climate scenarios, except for some areas in the Southern Ocean. There are clear changes in surface ocean DMS concentrations moving into the future, and they are attributable to changes in phytoplankton production and competition driven by complex spatially varying mechanisms. Comparisons between parallel simulations with and without DMS fluxes into the
\end{abstract}

Responsible Editor: Maren Voss.

S. Wang $(\bowtie) \cdot$ M. Maltrud $\cdot$ S. Elliott

The Climate Ocean and Sea Ice Modeling Group, Los

Alamos National Laboratory, MS B214, Los Alamos,

NM 87545, USA

e-mail: shanlinw@lanl.gov

P. Cameron-Smith

Atmospheric, Earth and Energy Division, Lawrence

Livermore National Laboratory, Livermore, CA, USA

A. Jonko

Earth and Environmental Sciences Division, Los Alamos

National Laboratory, Los Alamos, NM, USA atmosphere show significant differences in marine ecosystems and physical fields. Without DMS, the missing subsequent aerosol indirect effects on clouds and radiative forcing lead to fewer clouds, more solar radiation, and a much warmer climate. Phaeocystis, a uniquely efficient organosulfur producer with a growth advantage under cooler climate states, can benefit from producing the compound through cooling effects of DMS in the climate system. Our results show a tight coupling between the sulfur and carbon cycles. The ocean carbon uptake declines without DMS emissions to the atmosphere. The analysis indicates a weak positive phytoplankton-DMS-climate feedback at the global scale, with large spatial variations driven by individual autotrophic functional groups and complex mechanisms. The sign and strength of the feedback vary with climate states and phytoplankton groups. This highlights the importance of a dynamic marine ecosystem module and the sulfur cycle mechanism in climate projections.

Keywords Dimethyl sulfide - Climate simulation · Marine ecosystems · Phytoplankton

\section{Introduction}

Dimethyl sulfide (DMS) is a semivolatile organosulfur compound, mainly produced via enzymatic cleavage of the marine biogenic product dimethyl 
sulfoniopropionate (DMSP) (Andreae 1990; Kiene et al. 2000). After its emission into the atmospheric boundary layer, DMS is oxidized to sulfur dioxide $\left(\mathrm{SO}_{2}\right)$ and then sulfate $\left(\mathrm{SO}_{4}{ }^{2-}\right)$, which contributes to the formation of non-sea-salt sulfate aerosol (Andreae et al. 1985; Stefels et al. 2007). Though anthropogenic $\mathrm{SO}_{2}$ sources are much higher than the natural sources in the Northern Hemisphere (Bates et al. 1992), the importance of DMS in the global atmospheric sulfur budget has been documented since 1970s (Lovelock et al. 1972; Chin and Jacob 1996; Gondwe et al. 2003). Charlson et al. (1987) later postulated a feedback system involving marine phytoplankton, DMS, cloud albedo and climate. The proposed mechanism is known as the CLAW hypothesis, and it suggests that DMS produced by marine organisms is a crucial precursor of cloud condensation nuclei $(\mathrm{CCN})$ that regulates climate by modulating cloud albedo and therefore the radiation budget. The distribution and abundance of various phytoplankton and the subsequent production of DMSP respond to changing climate, which closes the feedback loop.

Considerable research efforts have been invested to examine the feedback loop suggested by the CLAW hypothesis (For example, Andreae et al. 1994, 1995; Bates et al. 1987; Gondwe et al. 2003; Leck et al. 1990; Sunda et al. 2002). Many laboratory and field studies have examined the mechanisms driving marine organosulfur production and there have been numerous measurements of the concentrations of DMS and DMSP. Results are synthesized and discussed in the series of publications by Kettle et al. (1999), Stefels et al. (2007), and Lana et al. (2011), etc. Over the past decade, more comprehensive DMS dynamics have also been incorporated in climate models to investigate the CLAW-type climate response and the associated effects on the radiative budget (Le Claiche et al. 2004; Buitenhuis et al. 2006; Six and Maier-Reimer et al. 2006; Bopp et al. 2008; Elliott 2009; Vogt et al. 2010; Wang et al. 2015). Though significant progress has been made in understanding the feedback, many of the biogeochemical processes involved are not well quantified, and large uncertainties remain (Ayers and Cainey 2007).

Multiple studies have focused on responses of the DMS flux to enhanced greenhouse gas concentrations (Gabric et al. 1998, 2001, 2004; Bopp et al. 2003; Kloster et al. 2007), since there is an urgent need to predict its role in climate change. For example, Gabric et al. (1998) and (2001) suggested the DMS flux would increase by $2-8 \%\left(2 \times \mathrm{CO}_{2}\right)$ using a slab ocean model and by $1-6 \%\left(3 \times \mathrm{CO}_{2}\right)$ with a coupled general circulation model in the future subantarctic Southern Ocean, respectively. Bopp et al. (2003) estimated DMS using total chlorophyll concentration and the trophic status ratio, and suggested a small overall increase of global DMS flux (2\%) under doubled $\mathrm{CO}_{2}$ condition, but with large regional variations. In a $\mathrm{CO}_{2}$ tripling scenario, Gabric et al. (2004) simulated a $14 \%$ increase in global DMS emission in the future, with the strongest regional enhancement of $106 \%$ between 50 and $60^{\circ} \mathrm{S}$. Vallina et al. (2007) concluded that the response of DMS flux to $\sim 50 \% \mathrm{CO}_{2}$ increase is small both globally ( $1.2 \%$ increase) and regionally $(<10-15 \%)$ using diagnostic equations expressing the DMS concentration as a function of mixed layer depth, chlorophyll concentration, and solar radiation dose. Kloster et al. (2007) simulated a global reduction of the DMS flux by $10 \%$ between 1861 and 1890 and 2061-2090 under the IPCC Special Report on Emissions Scenarios (SRES) A1B scenario. Another simulation using the SRES A1F1 scenario also showed reduced DMS fluxes over most regions except the Southern Ocean $\left(>60^{\circ} \mathrm{S}\right)$ where emissions increased by $170 \%$ (Cameron-Smith et al. 2011). Clearly, available studies from the last few decades of global biogeochemical modeling provide highly divergent predictions of DMS behavior under future conditions.

Furthermore, a number of publications have discussed the radiative effects of altered DMS fluxes. Present-day climate simulations with and without ocean DMS emissions suggested that the global mean top-of-atmosphere radiative forcing from DMS is $-2.03 \mathrm{~W} / \mathrm{m}^{2}$, with the strongest effect of $-16 \mathrm{~W} / \mathrm{m}^{2}$ between 30 and $70^{\circ} \mathrm{S}$ (Thomas et al. 2010). Jones et al. (2001) reported that doubling the DMS flux would reduce the net cloud forcing by $-1.38 \mathrm{~W} / \mathrm{m}^{2}$. Bopp et al. (2004) predicted a 3\% increase in the DMS flux under doubled $\mathrm{CO}_{2}$ conditions. They found negligible changes in the direct effect and an indirect effect of $-0.05 \mathrm{~W} / \mathrm{m}^{2}$. Using the elevated DMS flux simulated by Gabric et al. (2004) $\left(3 \times \mathrm{CO}_{2}\right)$, Gabric et al. (2013) estimated the global mean direct effect due to the DMS perturbation to be $-0.05 \mathrm{~W} / \mathrm{m}^{2}$ and the total radiative forcing to be $-0.48 \mathrm{~W} / \mathrm{m}^{2}$. Sensitivity simulations conducted by Gunson et al. (2006) showed significant impacts on the net cloud radiative forcing of -2 and $3 \mathrm{~W} / \mathrm{m}^{2}$ due to doubling and halving the 
DMS flux, respectively. Overall, previous research suggests a cooling effect of enhanced DMS emissions but quantitative effects on the energy budget are extremely variable.

Despite the rich literature on the topic, important questions remain regarding the CLAW hypothesis. It has been suggested that climate impacts on DMS production are small (Bopp et al. 2003; Gabric et al. 2001; Gunson et al. 2006; Vallina et al. 2007). Woodhouse et al. (2010) calculated the sensitivity of $\mathrm{CCN}$ to changes in the DMS flux using one data-based and several model-based DMS climatologies, and suggested a low sensitivity. Quinn and Bates (2011) further concluded that the CLAW hypothesis should be retired based on these two arguments as well as several others, including existence of non-DMS sources of CCN, contributions of sea spray aerosols to $\mathrm{CCN}$, and simulated weak DMS-cloud albedo climate feedback. Though the CLAW hypothesis may not provide a complete explanatory model of global climate regulation by marine aerosols, the contribution of DMS to CCN has been documented. Moreover, many predictions of future DMS flux were based on empirical relationships between DMS concentrations and other biological and physical properties, such as mixed layer depth, chlorophyll concentration, and solar radiation dose (Gabric et al. 1998, 2001, 2004; Bopp et al. 2003; Gunson et al. 2006; Vallina et al. 2007). The empirical approaches have been challenged and their inadequacies catalogued (Derevianko et al. 2009; Halloran et al. 2010). It has further been suggested that the overall confusion is due to poor understanding of some key factors, such as the response of $\mathrm{DMS}(\mathrm{P})$ to marine ecosystem change (Ayers and Cainey 2007; Carslaw et al. 2010), and more research may be needed. It is therefore necessary to estimate the production and removal of organosulfur compounds based on more comprehensive ecodynamics and sulfur cycling models. Moreover, the ecological roles of DMSP as an antioxidant, cryoprotectant, and antigrazing agent have not been fully investigated (Karsten et al. 1992; Wolfe and Steinke 1996; Stefels 2000; Sunda et al. 2002; Archer et al. 2010). The impact of DMS cycling on marine ecosystems via radiative forcing are not well understood, and neither are the subsequent effects on its production.

The work presented here estimates the production and fluxes of DMS under different climate scenarios using recently improved models for both the driving ecodynamics and marine sulfur cycling. These modeling improvements allow us to evaluate the complete biota-DMS-climate feedback loop for the first time using an Earth System Model without relying on empirical relationships. We assess impacts of DMS on biological production, phytoplankton community structure and the oceanic carbon cycle through radiative forcing by comparing simulations with and without DMS emissions. Finally, we also investigate how the impacts vary with climate.

\section{Methods}

\section{Model description}

This study makes use of the Community Earth System Model (CESM) version 1.2 (Hurrell et al. 2013), which includes not only physical components of the Earth system, but also super-fast atmospheric chemistry, a multi-mode aerosol model (Liu et al. 2012) and a set of ocean biogeochemical modules. Improved representations of the marine ecosystem structure and the sulfur cycle have also been incorporated (Wang et al. 2015). All simulations are performed with active atmosphere, land, sea ice, and ocean components in order to provide a complete backdrop for understanding the climate-marine biotic feedbacks. Below, we describe model features that are particularly relevant to the present work.

Analyses presented here focus mainly on processes/ changes in the atmosphere and ocean. The atmospheric general circulation model is the Community Atmosphere Model (CAM) version 5 (Neale et al. 2010). Simulations are conducted with the finite volume dynamical core of CAM5, with a horizontal resolution of $1.9^{\circ} \times 2.5^{\circ}$ and 30 vertical levels, extending to a height of $2.3 \mathrm{hPa}$ (around $40 \mathrm{~km}$ ). The aerosol scheme is the Modal Aerosol Model (MAM3) with three size bins: Aitken, accumulation and coarse modes (Liu et al. 2012). The computations involved are readily affordable at decadal and centennial scales. There are 15 transported aerosol tracers and 5 transported gas species, including $\mathrm{SO}_{2}, \mathrm{H}_{2} \mathrm{O}_{2}$, DMS, $\mathrm{H}_{2} \mathrm{SO}_{4}$, and a lumped semivolatile organic species. DMS emission from the ocean is balanced by the gas-phase oxidation processes. Comparing to a more complete version of the aerosol scheme known 
as MAM7, the simulated atmospheric burden and lifetime of DMS are quite similar (Liu et al. 2012). Cloud microphysics is calculated with a two-moment prognostic bulk scheme (Gettelman et al. 2008; Morrison and Gettelman 2008).

For atmospheric chemistry we use the "super-fast" atmospheric chemistry mechanism (Lamarque et al. 2012; Cameron-Smith, et al. 2006). Apart from the list of chemical reactions, the components of the atmospheric chemistry model are described and evaluated in Tilmes et al. (2015). The super-fast chemistry is designed for low-pollution regions (i.e., most of the planet), and to be computationally efficient. The super-fast mechanism uses 11 gas-phase species $\mathrm{CO}_{3}$, $\mathrm{OH}, \mathrm{HO}_{2}, \mathrm{NO}, \mathrm{NO}_{2}, \mathrm{HNO}_{3}, \mathrm{CO}, \mathrm{CH}_{2} \mathrm{O}, \mathrm{CH}_{3} \mathrm{O}_{2}$, $\mathrm{CH}_{3} \mathrm{OOH}$, isoprene) to calculate the oxidizing power of the atmosphere based on the methane oxidation pathways plus a simplified isoprene treatment.

The marine biogeochemical and DMS models run within the Parallel Ocean Program (POP) (Smith et al. 2010), the global ocean circulation component of CESM. POP has a nominal horizontal resolution of $1^{\circ}$ and 60 vertical levels, with finer latitudinal spacing near the Equator and enhanced vertical resolution for the surface ocean. The model simulates the ocean physical state adequately (Danabasoglu et al. 2012). Sea surface temperature and salinity in the present-day climate are well reproduced, with a small warm bias and a negative salinity bias (Danabasoglu et al. 2011; Bates et al. 2012). Though the model produces reasonable seasonal variation in its mixed layer depth (MLD), significant biases remain in some regions. For example, deep mixing is too weak in the Southern Ocean, the subtropical South Pacific and the northwest Pacific. Maximum MLD (XMLD) is generally overestimated in the Arctic Ocean. The impact of mixing biases on ocean biogeochemical cycles and biological production have been documented in previous literature (Wang et al. 2012; Long et al. 2013; Moore et al. 2013; Lindsay et al. 2014). The biases consequently affect the simulated DMS production via impacts on phytoplankton and nutrient distributions, though the effects cannot be exactly quantified due to intrinsic model limitations.

The global marine ecosystem is simulated using the Biogeochemical Elemental Cycling (BEC) module (Moore et al. 2002, 2004). Phytoplankton functional groups are the key players in the marine sulfur cycle. The intracellular sulfur content varies widely among autotrophic species (Stefels et al. 2007). Therefore, phytoplankton competition and community composition are crucial for the net DMS production (Vogt et al. 2010; Wang et al. 2015). We have recently added two new functional groups (Phaeocystis) that are important to the sulfur cycle into BEC (Wang et al. 2015), resulting in a total of five explicit phytoplankton functional groups (diatoms, diazotrophs, smaller phytoplankton, and two Phaeocystis groups for the North and South Hemispheres, respectively), and two implicit groups (coccolithophores and the general cyanobacteria) (Wang et al. 2015). Though Phaeocystis has multiple morphotypes, parameters of the groups are chosen based on the blooming colonial form (Wang and Moore 2011; Wang et al. 2015). The model also simulates multiple growth-limiting nutrients, key biogeochemical tracers and related processes. All major global ocean ecological and biogeochemical fields driving the DMS model are reproduced in a reasonable manner (Moore et al. 2002, 2004, 2013; Moore and Braucher 2008; Long et al. 2013; Wang et al. 2015).

Calculations of the production and removal of organosulfur compounds are driven by a complex set of biogeochemical fields and processes in the marine ecosystem. The intracellular sulfur levels are set according to the available laboratory measurements and field studies (Keller et al. 1989; Keller and Korjeff-Bellows 1996; Sunda et al. 2007; Stefels et al. 2007). The DMSP-to-nitrogen (DMSP:N) ratios of Phaeocystis, small phytoplankton, and diatoms are $0.3,0.1$, and 0.01 , respectively. Note that although Phaeocystis has the highest sulfur content, small phytoplankton can also make a significant contribution to oceanic DMS, while diatoms are less directly important in the sulfur cycle due to their low relative content. After being generated internally by phytoplankton, DMSP is released through lysis, grazing, and exudation. A fraction of this precursor molecule is converted into DMS through enzymatic cleavage. In addition to loss to the atmosphere, simulated removal terms for DMS are biological consumption, loss due to vertical (downward) mixing, and photochemistry, and biological oxidation. The model describes several critical processes suggested in previous field and laboratory studies. For example, the cellular sulfur content of phytoplankton in cold waters is elevated since DMSP functions as a cryoprotectant (Karsten et al. 1992; van Rijssel and Gieskes 2002). The 
simulated sulfur content also increases under nutrient limited conditions as suggested by Stefels et al. (2007).

In addition to coupling to a more realistic BEC ecodynamics, we have also implemented new knowledge gained in the past few years into the DMS model (Wang et al. 2015). For example, a high DMS yield factor in Phaeocystis dominated waters has been removed, which indicates that this group can be grazed, making their organosulfur subject to bacterial consumption. As a result, the simulated spatial and seasonal distributions are significantly improved (Wang et al. 2015). The sea-air DMS flux is calculated using a multicomponent sea-air gas transfer parameterization developed by Elliott (2009), which takes Henry's Law solubility into account and reduces the bubble transfer channel accordingly, in a manner specific to the properties of DMS. In our previous ocean and sea ice only hindcast experiments simulated global annual DMS emissions were $20.4 \mathrm{Tg}$ S/year (mean of the period 1990-2009). This is well within the canonical range of observationally based estimates (Wang et al. 2015). More detailed model description can be found in Wang et al. (2015) and some key model parameters are listed in Table 1.

The sea ice component in the CESM is the Community Ice CodE, version 4 (CICE4; Hunke and Lipscomb 2010), which has the same horizontal resolution as the ocean model. Sea ice coverage is simulated dynamically, but ice biogeochemistry is not included in this version. Though sea ice algae could contribute to the DMS production (Zemmelink et al. 2008; Trevena and Jones 2012), we do not consider emissions from ice in the present study. The land component is the Community Land Model (CLM4) (Lawrence et al. 2011). The performance of individual components and of the coupled CESM has been validated and documented in previous literature (Gent et al. 2011; Liu et al. 2012; Moore et al. 2013; Lindsay et al. 2014; Park et al. 2014; Wang et al. 2015).

\section{Numerical experiments}

To investigate changes in DMS production driven by climate, we conducted multiple time-slice simulations with our coupled model for pre-industrial, present day, and future climate scenarios. We prescribed the corresponding radiative forcings for each scenario, including spatially uniform greenhouse gas concentrations, anthropogenic nitrogen deposition, solar variability, and radiatively active aesosols (anthropogenic and natural, except for DMS). For example, $\mathrm{CO}_{2}$ concentrations used by surface components and the atmospheric radiation code are prescribed, instead of being prognostically computed. The marine ecosystem and biogeochemical cycles can only feedback to the climate system through DMS aerosol-cloudclimate interactions. This strategy eliminates climate variations induced by other factors. Forcing is held fixed at 1850 levels for pre-industrial cases (denoted as PI and PInoS), at 2000 values to represent the presentday state (PD and PDnoS), and at RCP8.5 2100 level for future climate (FUT and FUTnoS). We set up two parallel experiments for each climate state to study the DMS feedbacks on marine organisms and biogeochemical cycles: a case with dynamic DMS emissions to the atmosphere as the baseline and a case with the flux turned off during coupling. In PI, PD, and FUT, the DMS production is driven by inputs from the BEC, and the flux is determined using the gas exchange scheme in Elliott (2009). The values are calculated in the DMS model embedded in POP, and they are passed to CAM through the model coupler. Comparisons among these simulations show changes in the production and flux of DMS in response to climate. In PInoS, PDnoS, and FUTnoS, the DMS production and flux are also calculated in the DMS model, but the
Table 1 Key parameters used in the DMS module

${ }^{\mathrm{a}} d p s$ day per second, $1.1574 \times 10^{-5}$

\begin{tabular}{lll}
\hline Symbols & Values & Parameter description \\
\hline k_S_p_base & $0.1 * \mathrm{dps}^{\mathrm{a}}$ & Baseline phyto release to be augmented by grazing (1/s) \\
k_conv & $1.0 * \mathrm{dps}$ & First order constant for DMSP conversion $(1 / \mathrm{s})$ \\
k_S_z & $0.1 * \mathrm{dps}$ & First order constant for release from zooplankton $(1 / \mathrm{s})$ \\
k_S_B & $30.0 * \mathrm{dps}$ & Second order constant for bacterial consumption $(1 / \mathrm{s} / \mathrm{B})$ \\
k_bkgnd & $0.01 * \mathrm{dps}$ & Sulfur removal at low level in thermocline $(1 / \mathrm{s})$ \\
j_dms_perI & $0.005 * \mathrm{dps}$ & Coefficient for photolytic removal of DMS $\left(1 / \mathrm{s} / \mathrm{W} / \mathrm{m}^{2}\right)$ \\
\hline
\end{tabular}


information is not passed to the atmosphere. In other words, the sea-to-air DMS flux is zero in atmospheric calculations, but the marine sulfur cycle is allowed to respond to the DMS induced changes in the ocean. Comparisons between the parallel experiments show the role of DMS emissions in climate, modulation of DMS on the biological production and phytoplankton distribution, and the climate feedback on the organosulfur production. Though prescribed aerosol forcing varies between different climate scenarios, affecting the radiation at the sea surface, differences in photosynthetically active radiation (PAR) between the parallel experiments are consequences of DMS emission changes. The simulations are summarized in Table 2.

The ocean physical and biogeochemical state is initialized from the end of a 600-year sea ice-ocean coupled simulation (Wang et al. 2015), which was forced using repeated National Center for Environmental Prediction/National Center for Atmospheric Research (NCEP/NCAR) meteorological reanalysis data (Kalnay et al. 1996) but with a number of modifications for self-consistency (Large and Yeager 2009; Griffies et al. 2012). All other components, including sea ice, atmosphere, and land, are initialized from previous one-year runs conducted for the three different scenarios. Equilibration is relatively fast for the atmosphere and sea ice, and terrestrial radiative forcing is handled in a diagnostic mode. All experiments were run for 75 years, and since there is an initial adjustment period after full coupling, we only use the last 20 years for our analyses. Even so, small drifts exist in the perturbed experiments with DMS flux off and the 2100 control experiments. However, since we are focusing mainly on differences between paired simulations, prohibitively expensive equilibrium runs are not required here. The simulations are long enough to be indicative of adjustments of the physical system to radiative perturbations under different climate states. They are also long enough to allow processes in marine ecosystems to respond.

\section{Results and discussions}

Results are divided into three sections: changes in DMS production and emission with climate are discussed in "Variations in the DMS production and emission" section, impacts of DMS on marine ecosystems through modulated radiative forcing are investigated in "Impacts of DMS on the marine ecosystem" section, and evaluation of the CLAW hypothesis in "The CLAW hypothesis revisited" section. We also discuss how the impacts change from pre-industrial to present and future.

Variations in the DMS production and emission

Since phytoplankton are the producers of organosulfur and different autotrophic groups have distinct intracellular DMSP contents, it is crucial to understand marine ecosystem structure in any study of the marine sulfur cycle (Stefels et al. 2007). Processes influencing phytoplankton competition in the marine ecosystem are sensitive to details of the physical system. Phytoplankton growth is controlled by various factors, including macronutrient and iron availability, temperature and the light field. Except for the known high nitrate, low chlorophyll (HNLC) regions, growth of non $\mathrm{N}$-fixers is mostly limited by the local nitrogen concentration (Moore et al. 2013). Light availability also plays an important role at high latitudes, and it is affected by MLD and sea ice coverage (Wang and Moore 2011; Moore et al. 2013). Different autotrophic functional groups have diverse requirements for growth (Moore et al. 2002). For example, diatoms and Phaeocystis have relatively high half saturation constants for nutrient uptake, but lower grazing
Table 2 Simulation descriptions

\begin{tabular}{llll}
\hline Simulation & Climate state & Sea-to-air DMS flux & Forcing conditions \\
\hline PI & Pre-industrial & On & $\mathrm{CO}_{2}=284.7 \mathrm{ppm}, 1850$ forcings \\
PinoS & Pre-industrial & Off & $\mathrm{CO}_{2}=284.7 \mathrm{ppm}, 1850$ forcings \\
PD & Present day & On & $\mathrm{CO}_{2}=367 \mathrm{ppm}, 2000$ forcings \\
PdnoS & Present day & Off & $\mathrm{CO}_{2}=367 \mathrm{ppm}, 2000$ forcings \\
FUT & RCP8.5, 2100 & On & $\mathrm{CO}_{2}=954 \mathrm{ppm}, 2100$ forcings \\
FUTnoS & RCP8.5, 2100 & Off & $\mathrm{CO}_{2}=954 \mathrm{ppm}, 2100$ forcings \\
\hline
\end{tabular}


pressure, while small phytoplankton have higher nutrient uptake efficiency but suffer stronger grazing (Wang and Moore 2011). Thus, marine organisms will have complicated responses to climate change, as discussed in Moore et al. (2013), and these will subsequently affect DMS production and flux. We begin with a brief discussion of the simulated physical fields in different experiments, and the corresponding differences in marine ecosystems.

Global mean physical and biogeochemical fields from the last 20 years of each simulation are summarized in Table 3 and Fig. 1. Here we use the top of the model, defined as a constant pressure surface of $2.3 \mathrm{hPa}$, to approximate the top of the atmosphere (TOA). The TOA radiation is not balanced in these time slices (Table 3), but differences are significant when showing the responses and effects of DMS fluxes. Due to anthropogenic forcings, radiation imbalance during the modeled period increases from pre-industrial to future conditions. The accumulated energy in the system results in a slightly warmer sea surface and a decrease in sea ice area in the PD compared to PI. In addition, the annual mean PD MLD shows a modest decline. There is thus little change in the simulated global upper-ocean biogeochemical cycles (Table 3). However, there are significant changes to the physical system in the FUT scenario. These differences directly influence the light and temperature conditions experienced by marine organisms, in addition to modifying nutrient distributions through circulation and mixing. Compared with PI conditions, the mean sea surface temperature (SST) increases by $3.3{ }^{\circ} \mathrm{C}$ and sea ice area decreases by $\sim 58 \%$ in FUT. The mixed layer shoals by $\sim 10 \%$ on average, with even larger reductions in deep mixing, leading to a weaker entrainment of growth-limiting nutrients to surface waters. Dramatic reductions in surface macronutrient concentrations in most ocean regions result primarily from the differences in MLD (Fig. 1). Significant shifts in the

Table 3 Summary of global mean physical and biogeochemical fields of the last 20 years in experiments

\begin{tabular}{|c|c|c|c|c|c|c|}
\hline Simulation & PI & PinoS & PD & PdnoS & FUT & FUTnos \\
\hline Top-of-atmosphere radiation $\left(\mathrm{W} / \mathrm{m}^{2}\right)$ & 0.44 & 1.06 & 0.61 & 0.93 & 2.6 & 3.18 \\
\hline Sea ice area (September, millions of $\mathrm{km}^{2}$ ) & 19.53 & 13.95 & 17.19 & 12.66 & 8.25 & 6.34 \\
\hline Sea ice area (February, millions of $\mathrm{km}^{2}$ ) & 16.28 & 14.31 & 15.58 & 14.08 & 9.15 & 1.95 \\
\hline Sea surface temperature $\left({ }^{\circ} \mathrm{C}\right)$ & 18.7 & 19.72 & 18.86 & 19.74 & 22.04 & 23.34 \\
\hline Mixed layer depth (m) & 62.06 & 60.37 & 61.76 & 60.5 & 56.02 & 55.84 \\
\hline Photosynthetically active radiation $\left(\mathrm{w} / \mathrm{m}^{2}\right)$ & 64.02 & 66.81 & 62.64 & 64.46 & 64.14 & 66.71 \\
\hline Primary production (PgC/year) & 59.37 & 58.92 & 59.34 & 58.87 & 53.89 & 52.36 \\
\hline Export production (PgC/year) & 7.63 & 7.51 & 7.62 & 7.5 & 6.65 & 6.37 \\
\hline Air-sea $\mathrm{CO}_{2}$ flux $(\mathrm{PgC} / \text { year })^{\mathrm{a}}$ & 0.01 & 0.10 & -0.91 & -0.86 & -2.65 & -2.40 \\
\hline Small phytoplankton carbon biomass $\left(\mathrm{mmol} / \mathrm{m}^{3}\right)$ & 0.63 & 0.63 & 0.63 & 0.62 & 0.59 & 0.57 \\
\hline Diatom carbon biomass $\left(\mathrm{mmol} / \mathrm{m}^{3}\right)$ & 0.26 & 0.23 & 0.27 & 0.25 & 0.18 & 0.16 \\
\hline Diazotroph carbon biomass $\left(\mathrm{mmol} / \mathrm{m}^{3}\right)$ & 0.05 & 0.04 & 0.04 & 0.04 & 0.04 & 0.04 \\
\hline Phaeocystis carbon biomass $\left(\mathrm{mmol} / \mathrm{m}^{3}\right)$ & 0.13 & 0.10 & 0.13 & 0.11 & 0.06 & 0.05 \\
\hline Surface $\mathrm{NO}_{3}(\mathrm{uM})$ & 4.44 & 4.17 & 4.49 & 4.25 & 3.70 & 3.48 \\
\hline Surface $\mathrm{PO}_{4}(\mathrm{uM})$ & 0.527 & 0.473 & 0.509 & 0.465 & 0.375 & 0.340 \\
\hline Surface $\mathrm{SiO}_{3}(\mathrm{uM})$ & 7.32 & 6.96 & 7.23 & 7.07 & 6.66 & 6.64 \\
\hline Surface Fe (nM) & 0.512 & 0.536 & 0.505 & 0.518 & 0.606 & 0.647 \\
\hline Surface DMS (nM) & 2.30 & 2.23 & 2.30 & 2.23 & 1.96 & 1.89 \\
\hline DMS flux (Tg/year) & 19.74 & 19.61 & 19.62 & 19.39 & 18.14 & 17.81 \\
\hline
\end{tabular}

Note that simulations had not reached equilibrium, and differences between paired simulations show the effects of perturbations qualitatively

${ }^{a}$ Positive $\mathrm{CO}_{2}$ fluxes signify outgassing 
(a)
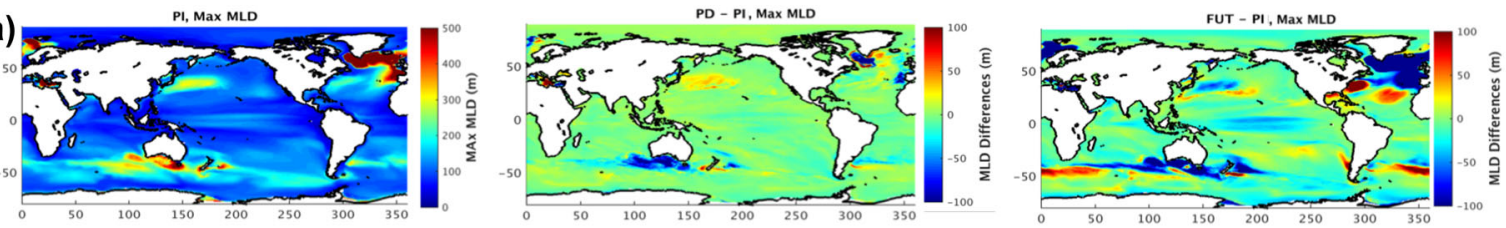

(b)
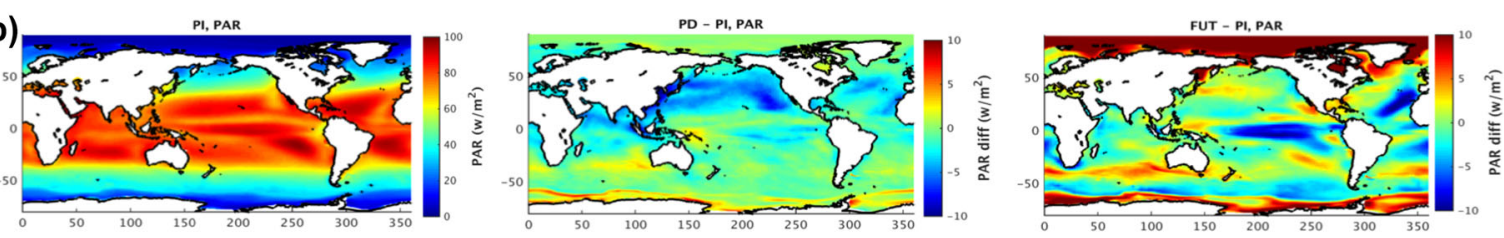

(c)
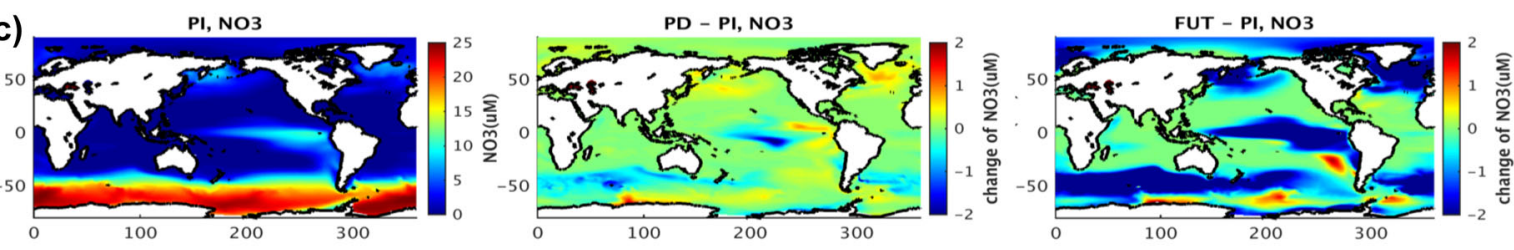

(d)
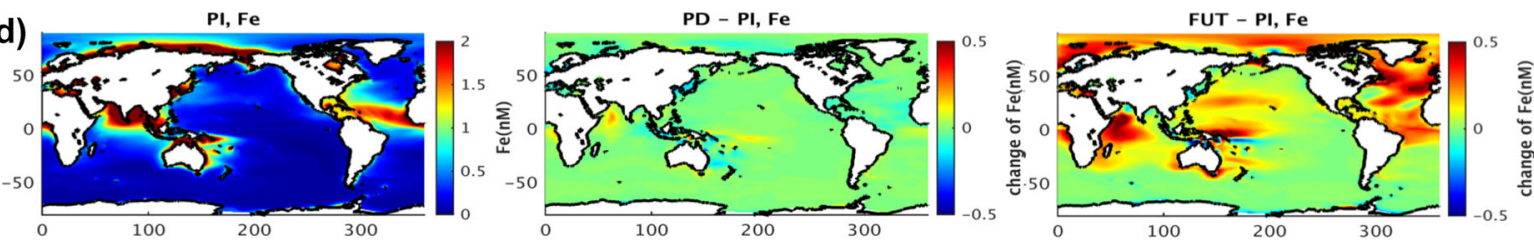

Fig. 1 (left) Annual mean sea surface nutrient distributions in PI, and differences (middle) between PD and PI, and (right) between FUT and PI. Panels show distributions a maximum MLD, b PAR, $\mathbf{c} \mathrm{NO}_{3}$, and $\mathbf{d} \mathrm{Fe}$

phytoplankton community composition occur, along with decreases in biological production (Fig. 2). The total primary and export productions are reduced by 9.2 and $12.8 \%$, respectively, suggesting an overall decrease in phytoplankton biomass due to lowered macronutrient availability and some shifts from larger autotrophs toward the modeled small phytoplankton group. Our marine ecosystem changes are largely consistent with previous simulations using a slightly different version of CESM (Moore et al. 2013).

Variations in the DMS fields link closely to changes in biological production and community composition. Comparisons between PI and PD states demonstrate regional differences in the DMS distributions over a seasonal scale. For example, atmospheric nitrogen deposition increases in the PD due to anthropogenic activities, which leads to elevated biomass of diatoms and Phaeocystis in the northwest Pacific during April and May (not shown). Since Phaeocystis species are the most efficient DMSP producers, the DMS concentrations increase during this time. There are also differences in the Southern Ocean due to shifts in small phytoplankton production, which are attributable to wind modulated nutrient supplies and light availability. Differences in DMS flux due to changes in wind are more obvious, especially in the Southern Ocean. Globally, however, DMS emissions are reduced by less than $1 \%$ in PD, which is within the range of interannual variability. While previous studies mainly focused on DMS production and flux in a warming climate (Bopp et al. 2003; Gabric et al. 1998, 2001, 2004), our simulations also compare marine DMS emissions between pre-industrial and contemporary climate states, and suggest that there is little difference in the global mean DMS concentration or total flux.

Changes in biological fields in the RCP8.5 future climate significantly modify the marine sulfur cycle (Table 3, Fig. 3). The global mean DMS concentration in FUT is $14.8 \%$ lower than PI. In general, differences in the sulfur distribution at high latitudes are controlled by Phaeocystis, while they are driven by small phytoplankton at low to midlatitudes. Due to changes in light and nutrient availability, Phaeocystis biomass is substantially lower in FUT, while small phytoplankton biomass increases in some regions as 

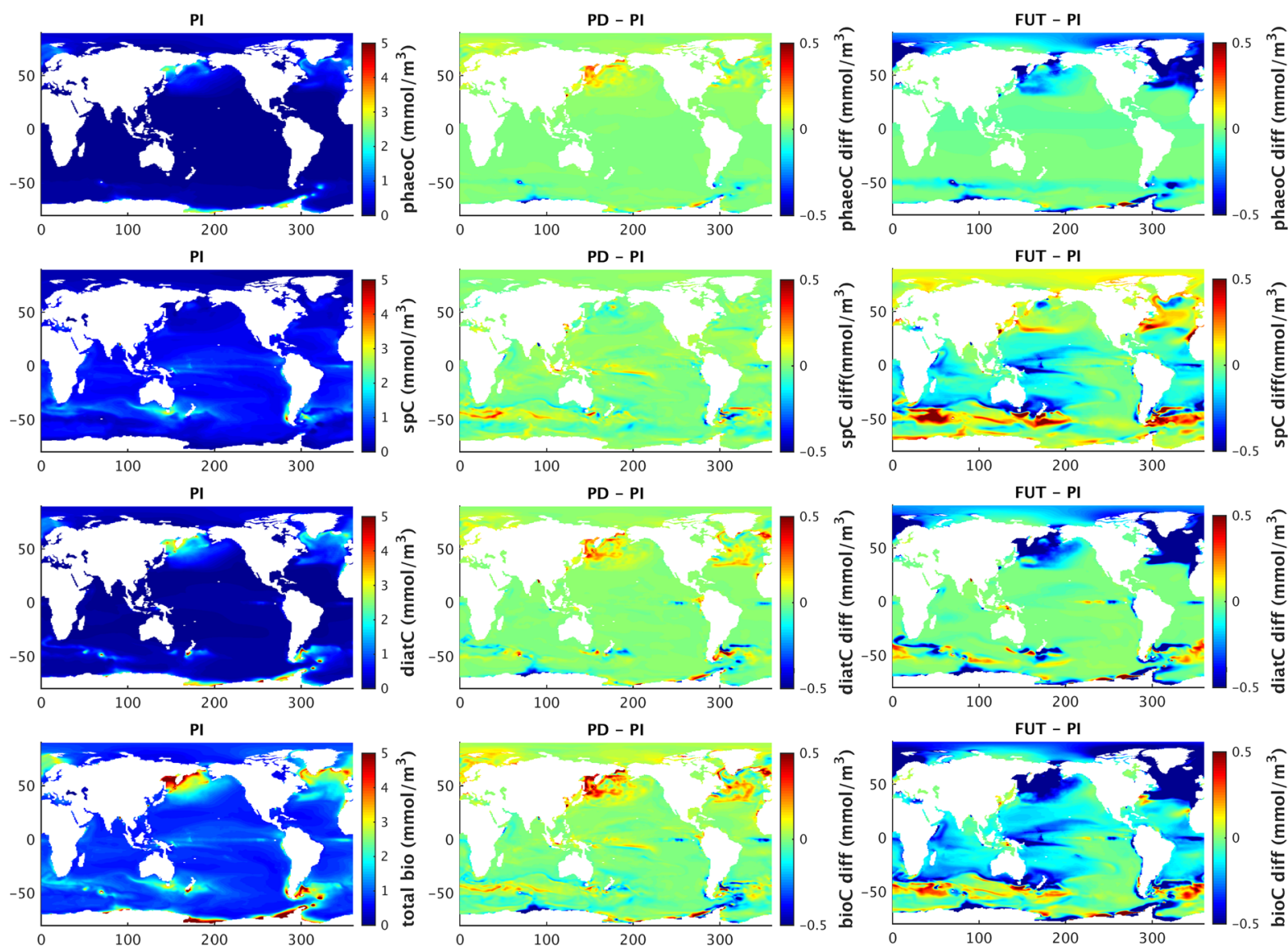

Fig. 2 Phytoplankton carbon biomass (left) PI, (middle) differences between PD and PI, and (right) differences between FUT and PI. Panels show annual mean Phaeocystis, small phytoplankton, diatoms, and total carbon biomass from top to bottom

this group is more efficient in nutrient uptake. Consequently, the DMS production by and large decreases under FUT conditions, attributable to an overall decrease in primary production, but especially the decrease in Phaeocystis production (Fig. 3). DMS concentrations in FUT are higher in the $40-50^{\circ} \mathrm{S}$
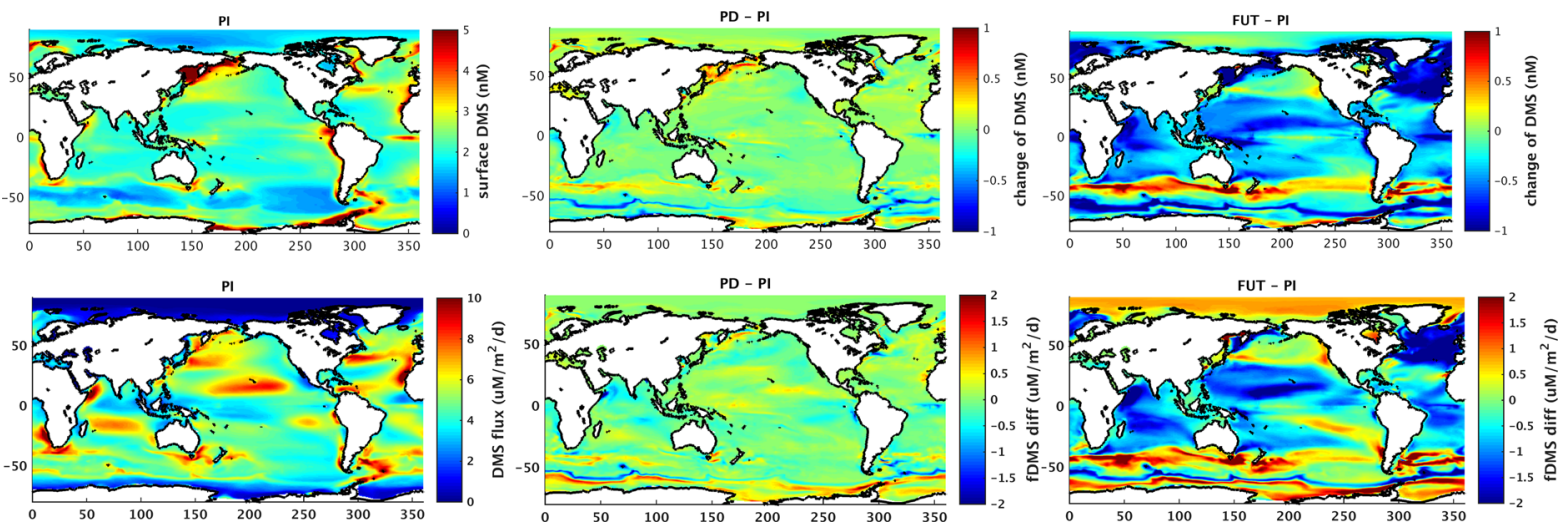

Fig. 3 (top) DMS concentrations and (bottom)DMS fluxes in (left) PI, and comparisons (middle) between PD and PI, as well as (right) between FUT and PI 
latitude band of the Southern Ocean (Table 4) mainly because of increased small phytoplankton production driven by higher iron availability (Moore et al. 2013). DMS concentrations at high latitudes in both hemispheres are also higher in FUT, due to an extended growing season along with sea ice reduction. Compared to the PI, the seasonality of DMS production at middle-high latitudes in FUT also shifts since phytoplankton phenology is altered in a warmer climate. In general, the DMS concentration peaks one month earlier in the northern hemisphere.

The global total DMS flux in FUT is $8.1 \%$ lower than the PI, which is not as large as the change in the DMS production. This is largely because changes in wind forcing also play important roles in gas exchange. The band of stronger westerly winds shifts toward Antarctica, which leads to relatively enhanced DMS fluxes over the Southern Ocean. Additional offline calculations using averaged winds from PD and surface DMS from FUT show that the DMS flux in FUT would be lower in the south subtropical Pacific and higher in the north Atlantic if there were no change in wind. Differences in sea ice area also play an important role in regulating DMS fluxes from open water at high latitudes. Emissions increase as sea ice coverage declines in a warmer climate. However, the total influence of sea ice loss on DMS emission is yet to be determined, since organosulfur compounds are also produced inside of sea ice (Elliott et al. 2012). Such processes are not simulated in the present study. Our reduction in the DMS flux generally agrees with the result of Kloster et al. (2007), in which the flux decreased by $10 \%$ globally. However, the midlatitude increase in DMS production due to higher small phytoplankton biomass was not represented by Kloster et al. (2007), because the DMS control mechanism is not based on individual phytoplankton groups in their study. Our results also disagree with several previous studies which projected an increase in the DMS flux in a warmer climate using algorithms independent of ecodynamics (Bopp et al. 2003; Gabric et al. 1998, 2001, 2004). This is not surprising, however, given that diagnosing DMS concentrations based on simple indicators such as mixed layer depth, chlorophyll concentration, and solar radiation dose has been shown to be problematic (Kloster et al. 2007; Derevianko et al. 2009; Halloran et al. 2010).
Table 4 Mean (a) DMS concentrations and (b) DMS fluxes distributed by latitude band

\begin{tabular}{|c|c|c|c|c|c|c|}
\hline Latitude & PI & PInoS & PD & PDnoS & FUT & FUTnos \\
\hline \multicolumn{7}{|c|}{ (a) Surface DMS concentrations (nM) } \\
\hline $90-80 \mathrm{~N}$ & 1.72 & 1.86 & 1.77 & 1.83 & 1.49 & 1.35 \\
\hline $80-70 \mathrm{~N}$ & 2.11 & 1.96 & 2.19 & 2.06 & 1.48 & 1.28 \\
\hline $70-60 \mathrm{~N}$ & 2.84 & 2.49 & 2.92 & 2.60 & 1.81 & 1.64 \\
\hline $60-50 \mathrm{~N}$ & 2.96 & 2.75 & 3.06 & 2.82 & 2.26 & 2.17 \\
\hline $50-40 \mathrm{~N}$ & 2.54 & 2.46 & 2.59 & 2.54 & 2.10 & 2.13 \\
\hline $40-30 \mathrm{~N}$ & 2.61 & 2.59 & 2.66 & 2.67 & 2.31 & 2.21 \\
\hline $30-20 \mathrm{~N}$ & 2.23 & 2.10 & 2.23 & 2.18 & 1.85 & 1.67 \\
\hline $20-10 \mathrm{~N}$ & 2.20 & 2.06 & 2.18 & 2.09 & 1.71 & 1.59 \\
\hline $10-0 \mathrm{~N}$ & 2.36 & 2.23 & 2.35 & 2.21 & 1.84 & 1.72 \\
\hline $0-10 \mathrm{~S}$ & 2.36 & 2.21 & 2.34 & 2.18 & 1.88 & 1.75 \\
\hline $10-20 \mathrm{~S}$ & 2.14 & 2.03 & 2.12 & 2.03 & 1.79 & 1.70 \\
\hline $20-30 \mathrm{~S}$ & 2.13 & 2.03 & 2.11 & 2.00 & 1.79 & 1.70 \\
\hline $30-40 \mathrm{~S}$ & 2.42 & 2.42 & 2.42 & 2.39 & 2.24 & 2.12 \\
\hline $40-50 \mathrm{~S}$ & 1.96 & 2.19 & 2.02 & 2.22 & 2.35 & 2.57 \\
\hline $50-60 \mathrm{~S}$ & 1.93 & 1.85 & 1.77 & 1.72 & 1.55 & 1.61 \\
\hline $60-70 \mathrm{~S}$ & 2.63 & 2.47 & 2.53 & 2.37 & 2.15 & 1.98 \\
\hline $70-80 \mathrm{~S}$ & 3.27 & 3.48 & 3.42 & 3.50 & 3.36 & 3.10 \\
\hline $80-90 \mathrm{~S}$ & $\mathrm{NaN}$ & $\mathrm{NaN}$ & $\mathrm{NaN}$ & $\mathrm{NaN}$ & $\mathrm{NaN}$ & $\mathrm{NaN}$ \\
\hline \multicolumn{7}{|c|}{ (b) Simulated oceanic DMS emissions (Tg/year) } \\
\hline $90-80 \mathrm{~N}$ & 0.01 & 0.02 & 0.01 & 0.02 & 0.04 & 0.06 \\
\hline $80-70 \mathrm{~N}$ & 0.10 & 0.11 & 0.10 & 0.11 & 0.11 & 0.12 \\
\hline $70-60 \mathrm{~N}$ & 0.18 & 0.17 & 0.19 & 0.18 & 0.13 & 0.13 \\
\hline $60-50 \mathrm{~N}$ & 0.60 & 0.58 & 0.61 & 0.59 & 0.50 & 0.52 \\
\hline $50-40 \mathrm{~N}$ & 0.93 & 0.92 & 0.92 & 0.91 & 0.81 & 0.84 \\
\hline $40-30 \mathrm{~N}$ & 1.31 & 1.31 & 1.31 & 1.33 & 1.19 & 1.14 \\
\hline $30-20 \mathrm{~N}$ & 1.47 & 1.39 & 1.48 & 1.45 & 1.29 & 1.14 \\
\hline $20-10 \mathrm{~N}$ & 2.11 & 2.02 & 2.10 & 2.03 & 1.73 & 1.60 \\
\hline $10-0 \mathrm{~N}$ & 1.66 & 1.60 & 1.64 & 1.57 & 1.33 & 1.24 \\
\hline $0-10 \mathrm{~S}$ & 1.59 & 1.50 & 1.53 & 1.42 & 1.33 & 1.27 \\
\hline $10-20 \mathrm{~S}$ & 2.05 & 1.97 & 1.99 & 1.87 & 1.83 & 1.76 \\
\hline $20-30 \mathrm{~S}$ & 1.70 & 1.63 & 1.69 & 1.58 & 1.51 & 1.43 \\
\hline $30-40 \mathrm{~S}$ & 1.97 & 2.01 & 1.95 & 1.95 & 1.88 & 1.78 \\
\hline $40-50 \mathrm{~S}$ & 1.90 & 2.14 & 1.90 & 2.07 & 2.24 & 2.47 \\
\hline $50-60 \mathrm{~S}$ & 1.51 & 1.54 & 1.48 & 1.51 & 1.43 & 1.53 \\
\hline $60-70 \mathrm{~S}$ & 0.60 & 0.63 & 0.66 & 0.70 & 0.69 & 0.70 \\
\hline $70-80 \mathrm{~S}$ & 0.05 & 0.07 & 0.06 & 0.08 & 0.09 & 0.09 \\
\hline 80-90 S & 0.00 & 0.00 & 0.00 & 0.00 & 0.00 & 0.00 \\
\hline Total & 19.74 & 19.61 & 19.62 & 19.39 & 18.14 & 17.81 \\
\hline
\end{tabular}


Impacts of DMS on the marine ecosystem

To better predict the future marine sulfur cycle and to understand the impacts of DMS on marine ecosystems through regulation of the radiation budget, we conducted sensitivity simulations in which the DMS flux into the atmosphere is set to zero. The suppression of DMS flux from the surface ocean to the atmosphere has significant effects on several aspects of global climate, including clouds and the marine ecosystem. Though the effects of the sulfur flux on clouds and the climate are explicitly simulated, here we focus on changes in the physical system and on influences on marine organisms. Some results are summarized in Table 3. Comparisons between simulations with and without the DMS flux into the atmosphere show significant decline in atmospheric sulfate aerosol burden over the vast oceans, which causes differences in cloud fraction and cloud radiative forcing (Fig. 4). Turning off the marine biogenic sulfur emission results in a net radiative forcing of $0.32-0.62 \mathrm{~W} / \mathrm{m}^{2}$ during the last 20 years of the time slices (Table 3 and Fig. 4), which implies a cooling effect of DMS. The first year top-of-model radiative effect of DMS is $1.75 \mathrm{~W} / \mathrm{m}^{2}$ under the contemporary scenario. This is smaller but comparable to an estimate of $2.03 \mathrm{~W} / \mathrm{m}^{2}$ reported by Thomas et al. (2010). As a result of the radiative forcing, the global mean SST increases by 0.9-1.3 ${ }^{\circ} \mathrm{C}$ during the last 20 years, with patterns similar to projected warming induced with enhanced greenhouse gases emissions (Table 3 and Fig. 4).

As a consequence of surface warming, ocean stratification increases significantly, with large spatial variations (Fig. 4). Maximum monthly MLD in the North Atlantic decreases by more than $300 \mathrm{~m}$ in preindustrial and present-day parallel experiments. Differences of maximum MLD between FUT and FUTnoS are less significant, as deep convective mixing is much reduced in the warm FUT climate. Both summer and winter sea ice areas decrease significantly without the DMS flux, especially under the future climate scenario (Table 3). Compared to the Southern Hemisphere, there are larger impacts on Arctic sea ice due to asymmetric warming. In preindustrial and present day simulations, September sea ice areas in the Arctic are reduced by $\sim 84 \%$ and $71 \%$, respectively, while February sea ice areas decrease by 6 and $7 \%$, respectively. In the future scenario, the February sea ice area decreases by $79 \%$ in the Arctic and no sea ice at all in September in FUTnoS.

These differences in the physical system lead to significant changes in PAR and nutrient distribution, which in turn affect phytoplankton biomass and biogeochemical cycles. Phytoplankton growth is often limited by nitrogen and iron in the surface ocean (Moore et al. 2013), while light availability also plays an important role in controlling photosynthesis (Wang and Moore 2011). Without the DMS flux, reduced cloud cover and sea ice area both allow more shortwave radiation to reach the surface ocean, increasing the intensity of PAR (Fig. 4). Additionally, changes in stratification significantly alter the mixing of nutrients to surface waters. Thus, phytoplankton biomass and competition are significantly different in simulations without DMS flux (Fig. 5).

We use comparisons between two pre-industrial time slices (PI and PInoS) to discuss the impacts of DMS on marine ecosystems via regulating radiative forcing. Compared to the PI, the surface ocean warms and stratification increases in PInoS, similar to differences we see between PI and FUT but to a lesser extent. In PInoS, annual mean surface concentrations of nitrate, phosphate, and silicate are lowered by 6,10 , and 5\%, respectively, with respect to PI (Table 3 ). Declining nitrate concentrations lead to increasing $\mathrm{N}$-limitation for the growth of DMSP producers in most non-HNLC regions. There are also modest increases in surface iron concentrations due to lower consumption and scavenging losses associated with lower phytoplankton biomass. Excess iron is transported laterally to HNLC regions, where it is rapidly consumed by phytoplankton. Thus, primary and export productions decrease in $\mathrm{N}$-limited regions, including the Indian and Atlantic regions, but increase in the Southern Ocean. Overall, global primary and export productions decrease 0.4 and $0.1 \mathrm{PgC} / \mathrm{year}$, respectively.

Decreased nutrient availability tends to favor small phytoplankton, which have lower half saturation constants for the various nutrients. This leads to the replacement of diatoms and Phaeocystis by small phytoplankton within the autotrophic community in the PInoS case, especially in polar regions. The total production of small phytoplankton increases by 0.6 $\mathrm{PgC} / \mathrm{year}$, and the fraction contributed by this group to global primary production increases $1 \%$. The increased small phytoplankton biomass at middle to 
(a)

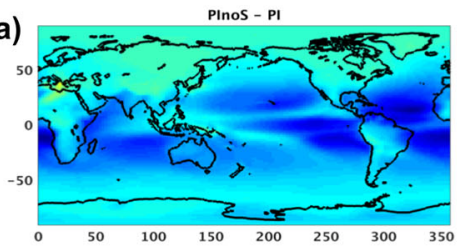

(b)

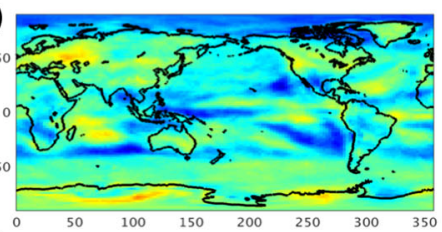

(c)

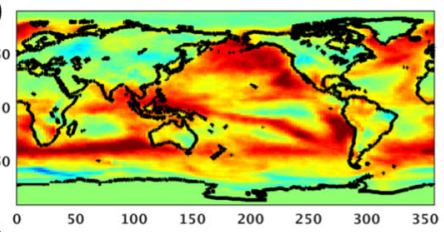

(d)

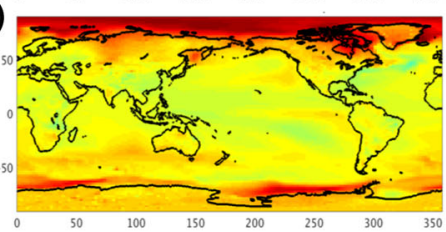

(e)

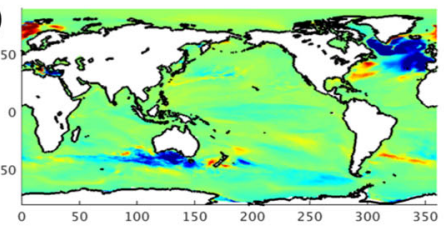

(f)

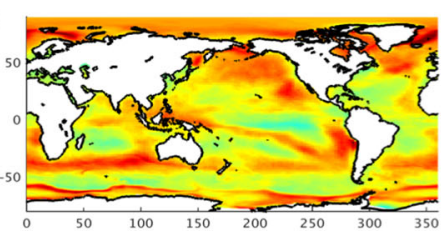

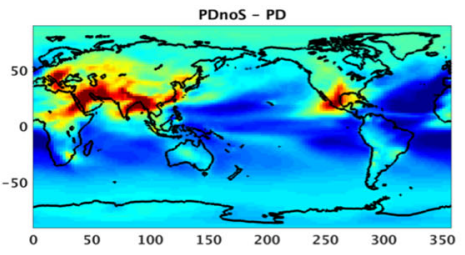
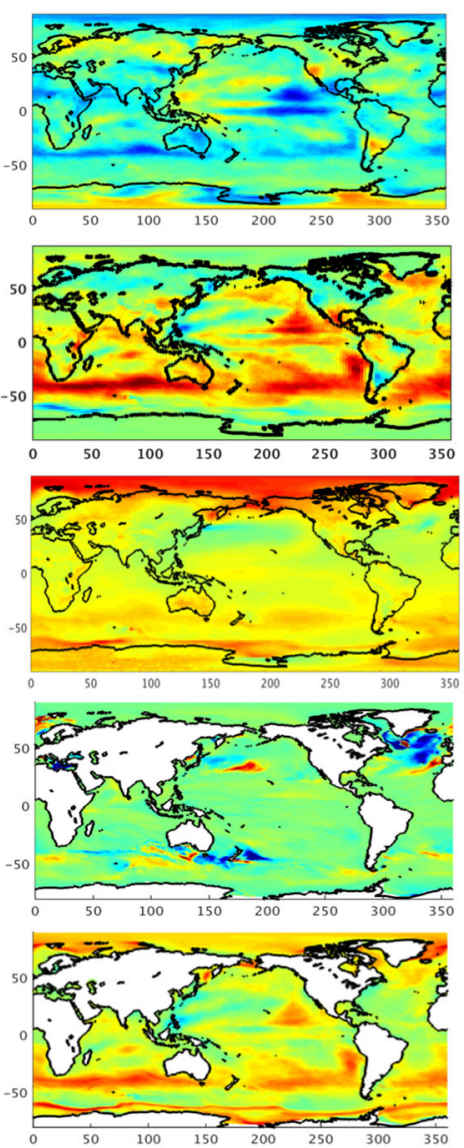
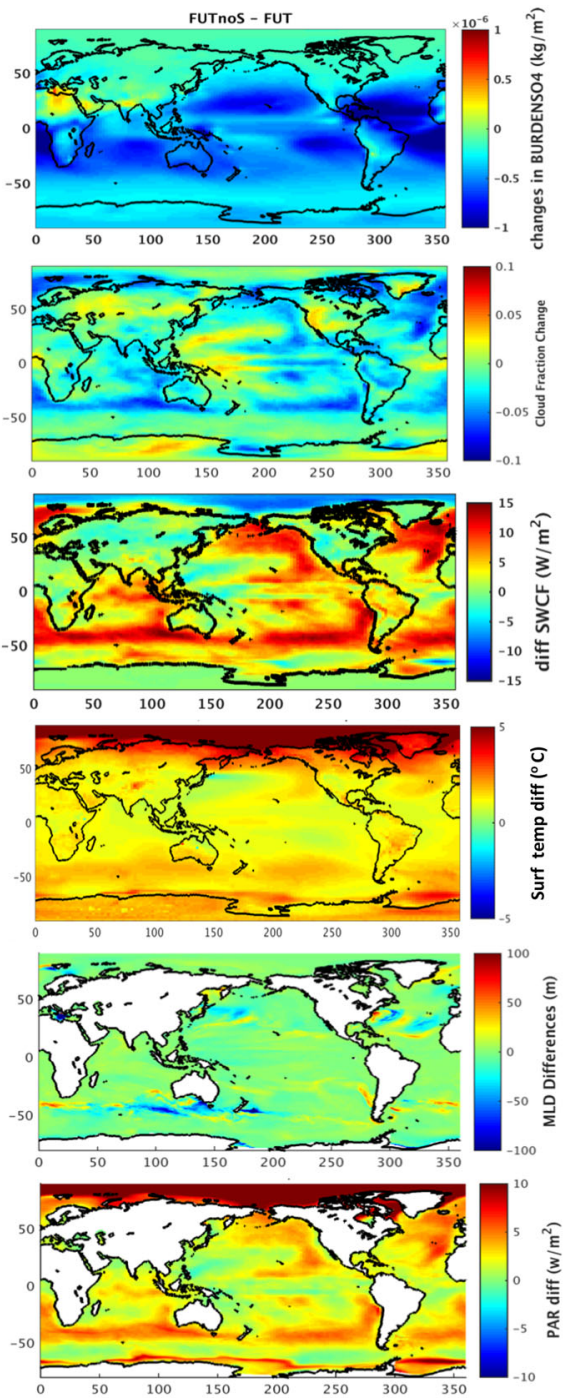

Fig. 4 Comparisons of annual mean a sulfate aerosol burden, b cloud fraction, c shortwave cloud forcing, d sea surface temperature, e maximum MLD, and $\mathbf{f}$ PAR between parallel experiments for PI (left), PD(middle) and FUT(right), with and without DMS to the atmosphere high latitudes is partly compensated by the decreasing biomass in oligotrophic waters. The mean surface carbon biomass concentrations of Phaeocystis and diatoms decrease by 0.03 and $0.02 \mathrm{mmolC} / \mathrm{m}^{3}$, respectively. However, the vertically integrated biomass of Phaeocystis decreases slightly more than diatoms due to a larger reduction in Phaeocystis in deeper waters. This occurs because the modeled Phaeocystis has a higher alpha value (the chlorophyll specific initial slope of photosynthesis-irradiance curve), which makes the group more competitive under low light conditions. In the PInoS, more light becomes available for photosynthesis under a lower cloud cover and a shallower mixed layer. Thus, the fraction of Phaeocystis decreases in deep mixing regions as it loses its advantage in the competition. The vertically integrated phytoplankton biomass increases in association with increasing PAR in the north Pacific, the Arctic, midlatitudes of the Southern Ocean, and Antarctic coastal waters. The increased 

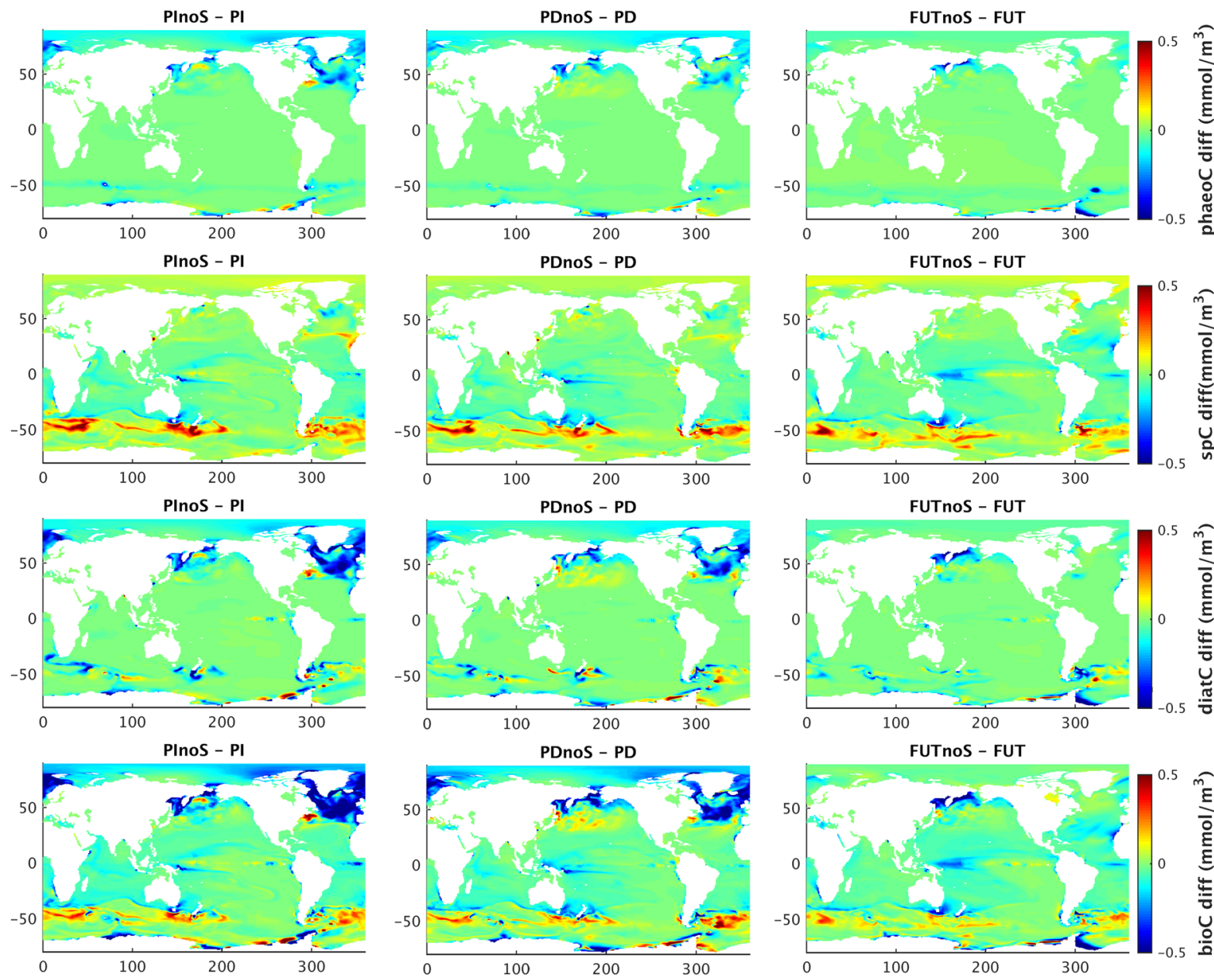

Fig. 5 Differences in Phaeocystis, small phytoplankton, diatom, and total carbon biomass (left) between PInoS and PI, (middle) between PDnoS and PD, and (right) between FUTnoS and FUT

primary production in polar waters is also a result of a prolonged growing season associated with sea ice decline, as phytoplankton community composition shifts significantly during these periods. As sea ice declines, Phaeocystis biomass increases in November in Antarctic coastal waters, but the group is quickly replaced by small phytoplankton when nutrient availability falls. Similar variations when comparing PInoS and PI are also observed in the north Pacific and north Atlantic. In the absence of a global DMS flux, the enhanced growth of Phaeocystis starts earlier, as the mixed layer shoals and sea ice melts. But the biomass is lower in May through June while this group is being replaced by small phytoplankton. As a result of changes in biological production and in several physical fields, the global $\mathrm{CO}_{2}$ flux changes from
0.01 to $0.10 \mathrm{PgC} /$ year, making the ocean a weak source of $\mathrm{CO}_{2}$.

Impacts of turning off the biogenic sulfur emission are similar in pre-industrial and future time slices, but weaker in contemporary climate, due to the effects of large anthropogenic aerosol emissions. As a result, influences on biogeochemical cycles and primary production have similar patterns in the two scenarios, but differences between PD and PDnoS are smaller. Impacts of the DMS flux are similar over most ocean regions in the future scenario, except polar regions where the modification leads to extensive changes in the physical system. Differences in biogeochemical tracers between FUTnoS and FUT are smaller at middle to high latitudes of the northern hemisphere than the pre-industrial and present day scenarios 
because diatom and Phaeocystis groups have been largely replaced by small phytoplankton in the FUT. The primary and export production values decrease $\sim 1.5$ and $0.3 \mathrm{PgC} /$ year, respectively, in FUTnoS (Table 3). The global oceanic $\mathrm{CO}_{2}$ sinks simulated during the final 20-year period in PDnoS and FUTnoS weaken 5.5 and $9.4 \%$, respectively (Table 3).

\section{The CLAW hypothesis revisited}

The CLAW hypothesis proposed a feedback loop between phytoplankton, DMS, and climate. In our "no DMS" cases (PInoS, PDnoS, and FUTnoS), the DMS production and flux are simulated by the ocean model, even though the incoming flux is set to zero in the atmospheric calculations. As described above, significant changes are observed in the physical and biogeochemical systems in the simulations without DMS fluxes. Therefore, differences in DMS concentrations and fluxes calculated by the model between parallel experiments (Fig. 6) can be used to evaluate the phytoplankton-DMS-climate feedback. Comparison of DMS distributions between two parallel simulations (PI and PInoS, for instance) shows that changes in concentrations are driven by responses of marine organisms to turning off the DMS flux (Fig. 6, Table 4).

Compared with PI, the DMS concentrations in PInoS are generally lower in oligotrophic subtropical gyres, as phytoplankton biomass decreases with increasing stratification. At middle to high latitudes, simulated DMS distributions are mainly attributable to the combination of Phaeocystis and small phytoplankton. In the Northern Hemisphere, there are significant differences in DMS concentrations from April to October. Excluding some areas of the north Atlantic where deep mixing collapses, Phaeocystis biomass is higher in April in PInoS, which leads to higher DMS concentrations in surface waters of the north Pacific and Atlantic. The biomass of this phytoplankton group then decreases from May to July as a result of lower nitrate availability, while small phytoplankton biomass increases during April and October due to higher efficiency nutrient uptake. The higher biomass of small phytoplankton can also be attributed to lower sea ice extent. Since the intracellular sulfur to carbon ratio of Phaeocystis is about 3 times that of small phytoplankton and 30 times the diatom value in our model, DMS distributions are dominated by Phaeocystis and concentrations are lower in PInoS in May and June over most regions of the north Pacific, Atlantic and Arctic. Influences of small phytoplankton emerge in July and dominate changes in DMS distributions from August to October in the northern hemisphere. The simulated relationship between changes in the sulfur cycle and sea ice extent agree with previous observational studies (Sharma et al. 2012; Browse et al. 2014). Similarly, changes in the DMS production appear mainly from October to the following March in the Southern Hemisphere as a result of the combined impacts of small phytoplankton and Phaeocystis groups. Phaeocystis biomass increases early in the growth season, but is quickly replaced by small
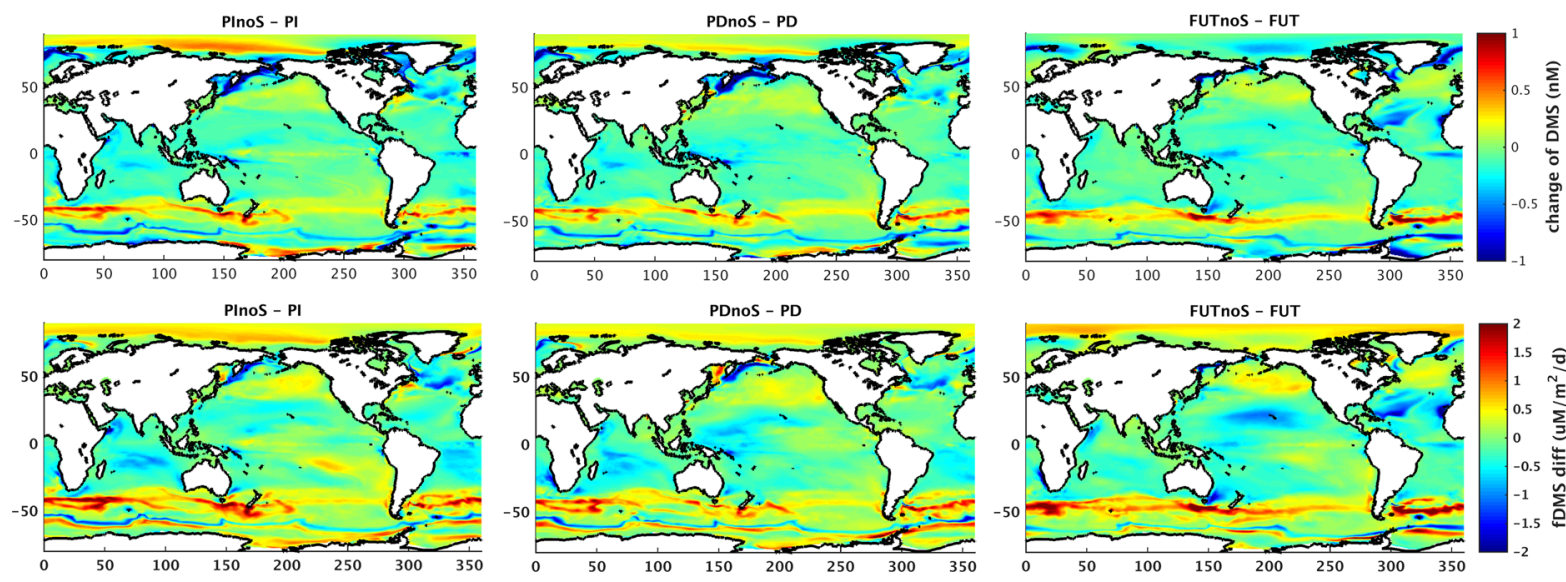

Fig. 6 Simulated responses of (top) oceanic DMS concentrations and (bottom) emissions after removing DMS in atmospheric calculations. Panels are (left) pre-industrial, (middle) present and (right)future 
phytoplankton. As a result, changes in Phaeocystis contribute to a reduction in DMS production on an annual scale, while increases in small phytoplankton result in higher DMS production in the mid-latitude Southern Ocean.

Overall, the annual mean DMS concentrations in PInoS are higher in the central Arctic, north Pacific subtropical gyre, $35-50^{\circ} \mathrm{S}$ of the Southern Ocean and some regions along the Antarctic coast, but are lower in most remaining surface waters (Fig. 6). The global mean DMS concentration decreases from 2.30 to $2.23 \mathrm{nM}$ when DMS is ignored by the atmosphere. Differences in the flux patterns between PInoS and PI largely follow changes in surface DMS distributions, with influences from the wind field. If no DMS enters the atmospheric calculations, further changes in the global total DMS flux are small (less than 1\%). However, there is large spatial variability in the differences (Fig. 6, Table 4), resulting from interactions between complex processes. Our simulations suggest that Phaeocystis and diatoms contribute to a positive phytoplankton-DMS-climate feedback during the pre-industrial period, while the feedback resulting from changes in the small phytoplankton group is more complex; it is negative at middle to high latitudes and positive in subtropical gyres in general. The sign of the overall phytoplankton-DMS-climate feedback loop is determined by individual dominant groups, and varies spatially. The feedback is negative in the central Arctic, north Pacific subtropical gyre, $35-50^{\circ} \mathrm{S}$ of the Southern Ocean and the Antarctic coast, but positive in other regions.

The phytoplankton-DMS-climate feedback also varies with/depends on the background climate state. As discussed in "Impacts of DMS on the marine ecosystem" section, Phaeocystis and diatoms are largely replaced by small phytoplankton at high latitudes under future climate. As a result, the feedbacks in these regions are largely dominated by small phytoplankton. Growth of this group starts earlier due to sea ice changes in FUTnoS, but biomass decreases over the course of the following 2 months due to increasing nutrient limitation. Thus, FUTnoS DMS production increases in March and April in the Arctic, but annual mean DMS concentrations decrease. The story is similar for the Antarctic coast. As a result, the sign of small phytoplankton-DMSclimate feedback becomes positive at high latitudes. Compared to the pre-industrial period, the overall feedback is more positive under a warmer climate. Though climate changes significantly without oceanic DMS emissions, the simulated response of global DMS fluxes to removing DMS in the atmosphere are generally less than $2 \%$. This suggests a small positive feedback at the global scale, with significant spatial variations and a dependence on the background climate.

Globally, the phytoplankton-DMS-climate feedback is small, though DMS emissions play an important role in the climate system, as discussed in the previous section. This is because of complicated responses of marine ecosystems to the altered physical and chemical conditions. Therefore, an understanding of the phytoplankton community composition and its potential changes is needed to evaluate the overall phytoplankton-DMS-climate feedback. In recent years, it has become clear that the CLAW hypothesis failed to acknowledge other sources of $\mathrm{CCN}$ and processes regulating aerosol-cloud cycles (e.g., Quinn and Bates 2011; Green and Hatton 2014). Nonetheless, the present work shows that DMS does play a significant role in global climate regulation by marine aerosols, including a secondary positive phytoplankton-DMS-climate feedback via the oceanic carbon cycle. The contribution of organic matter, sea salt, and non-sea-salt $\mathrm{SO}_{4}{ }^{2-}$ to $\mathrm{CCN}$ and cloud formation must be included in future modeling studies to more completely understand marine aerosol feedbacks. We are therefore adding these processes to our next generation Earth System Model.

\section{Summary}

In the present study, we have conducted time-slice simulations using a fully coupled Earth system model including improved dynamic ocean ecosystem/biogeochemistry and marine sulfur cycle modules (Wang et al. 2015). Motivations for this work include (1) examination of variations in the DMS flux, (2) investigation of the influence of DMS on processes in marine ecosystems as it passes through the atmospheric aerosol, and (3) evaluation of the CLAW hypothesis. Since DMS emanating from the ocean is a source of CCN and contributes to cloud formation, it is important to estimate potential changes in DMS emissions when looking at how clouds might change with global warming (Cameron-Smith et al. 2011). 
Differences of DMS production and emission between different climate scenarios vary significantly, with larger differences associated with more altered climate. Comparisons of time slices show that differences in surface ocean DMS distributions and fluxes to the atmosphere between pre-industrial and presentday scenarios are negligible. However, in the 2100 time slice the mean concentration decreases by $0.34 \mathrm{nM}(17.8 \%)$ and the annual flux is $8.1 \%$ lower, with significant spatial variability (Table 4 and Fig. 6). Our simulations further show that the future DMS flux increases at high latitudes in both hemispheres and over the latitude band $35-50^{\circ} \mathrm{S}$ across the Southern Ocean. But marine emissions decline in most other regions, with all the differences driven largely by changes in biological production and shifts in phytoplankton community structure. Declining sea ice coverage also plays an important role in determining the DMS flux at high latitudes.

We use simulations with a complete shutdown of DMS flux into the atmosphere as an extreme scenario for testing and exploring reduced DMS emissions at the global scale, allowing us to assess impacts of DMS on biological production, phytoplankton community structure and the carbon cycle. Based on these results, it is clear that oceanic DMS flux plays an important cooling role in the climate system, and that physical fields, such as temperature, circulation, and sea ice, are significantly different without atmospheric DMS. All of these impacts have a sulfur connection associated with the effect of aerosols on radiation, both by the aerosols scattering light and the aerosols affecting clouds. Altered radiative forcing strongly modifies physical and chemical conditions supporting marine organisms, across basin scale ecosystems. Differences in nutrient availability, mixing and the light regime lead to overall smaller biological production and shifts in phytoplankton community composition. While the biomass of diatoms and Phaeocystis is significantly less, we observe more small phytoplankton biomass in the north Pacific, north Atlantic, Arctic, and some regions in the Southern Ocean. In addition, weaker DMS emission will likely decrease oceanic $\mathrm{CO}_{2}$ uptake largely due to warming effects, a secondary impact of DMS on climate via the carbon cycle that has not been noted in previous studies.

Responses of DMS production and surface ocean emission to turning off the atmospheric flux are driven mainly by changes to the marine ecosystems, especially phytoplankton community composition. Our results suggest that reducing DMS flux in a cooler climate will stimulate the production of this compound in the central Arctic, Pacific subtropical gyre, $35-50^{\circ} \mathrm{S}$ of the Southern Ocean and some regions near the Antarctic. But a positive feedback is recorded in the remaining areas-meaning most of the surface ocean at lower latitudes. This feedback pattern changes under a warmer base climate, where positive phytoplankton-DMS-climate feedback is observed over more ocean areas. Due to the complexity of resulting marine ecosystem change, there is large spatial variability in our extreme scenario phytoplanktonDMS-climate feedback. Moreover, Woodhouse et al. (2013) showed that the CCN sensitivity to changes in the DMS flux varies spatially by a factor of $>20$. Thus, it is necessary to model marine ecosystems dynamically and the marine sulfur cycle explicitly in order to better evaluate the role of DMS in the climate system. Further studies to provide insights in regional climate sensitivity to phytoplankton and DMS are also needed.

Taken at the global scale, our simulations with and without DMS suggest a small positive feedback, which is consistent across climate scenarios, though spatial patterns and mechanisms may differ between climate states. The significant spatial variability in feedback patterns is driven mainly by individual autotrophic functional groups. Furthermore, the sign and strength of feedback loops involving different phytoplankton groups varies. The overall sign of the feedback disagrees with some previous studies (Bopp et al. 2004; Gunson et al. 2006; Gabric et al. 2013). This discrepancy can be attributed to the coupling between a dynamic marine ecosystem module and the sulfur cycle mechanism adopted in the current simulations.

The predicted changes in the DMS flux in the future may be underestimated in this study due to certain limitations in our treatment of the ecosystem and sulfur dynamics. For example, Prochlorococcus and Synechococcus dominate the autotrophic biomass in oligotrophic waters, but contribute little to the DMSP production (Stefels et al. 2007). It is predicted that the biomass of these non-DMSP producers will increase in a warmer climate (Flombaum et al. 2013), which will affect DMS emission at low to middle latitudes. This shift is not fully simulated by our model since the cyanobacteria are represented implicitly. Six et al. 
(2013) have recently suggested that reduced DMS emissions will result from ongoing ocean acidification. In their simulations, the changing $\mathrm{pH}$ conditions operate through the sulfur cycle and generate significant climate impacts. The influence of acidification is not considered in the current study. Moreover, physiological parameters for individual phytoplankton groups are set based on studies in the past decades, which may not represent the phytoplankton species under the future climate. Note that the time slice simulations of present-day and future scenarios have not continued long enough to reach their full steady states in this study, and a certain amount of drift remains in physical and biogeochemical fields. Differences between these scenarios and the pre-industrial case may therefore be somewhat underestimated. Impacts of DMS on marine ecosystems and the oceanic carbon uptake which occur through modified radiative forcing are also likely to be underestimated as the climate system evolves. However, our conclusions should hold qualitatively for simulations of the transient climate and at steady state.

It has recently been suggested that the phytoplankton-DMS-climate feedback forming the core of the CLAW hypothesis is an oversimplification. Marine ecosystems-aerosol-cloud system interactions are extraordinarily complex and involve a poorly understood mix of biogenic marine aerosols (Quinn and Bates 2011; Green and Hatton 2014). It will likely prove necessary to take other marine biogenic aerosol precursors into consideration in climate projections. Our simulations employ an ecosystem model of intermediate complexity, but more detailed marine ecosystem structural representations could modify our conclusions since DMS production and flux are largely controlled by shifts in community composition. The present study provides sensitivity tests based on our current level of knowledge and state of the art Earth system modeling. To better understand and quantify the climate uncertainties involved, further improvements of our models are needed, in addition to measurements and laboratory studies.

Acknowledgements This research has been supported by several grants from the U.S. Department of Energy's Office of Science. These include a Regional and Global Climate Modeling Science Focus Area project (RGCM SFA) administered by COSIM (Climate Ocean Sea Ice Modeling) at Los Alamos National Laboratory, and the SciDAC (Scientific Discovery through Advanced Computing) study ACES4BGC
(Applying Computationally Efficient Schemes for Biogeochemical Cycles). The work by P. Cameron-Smith was performed under the auspices of the U.S. Department of Energy by Lawrence Livermore National Laboratory under Contract DE-AC52-07NA27344. Computational facilities were provided by Institutional Computing resources at Los Alamos National Laboratory.

Open Access This article is distributed under the terms of the Creative Commons Attribution 4.0 International License (http:// creativecommons.org/licenses/by/4.0/), which permits unrestricted use, distribution, and reproduction in any medium, provided you give appropriate credit to the original author(s) and the source, provide a link to the Creative Commons license, and indicate if changes were made.

\section{References}

Andreae MO (1990) Ocean-atmosphere interactions in the global biogeochemical sulfur cycle. Mar Chem 30(1-3): 1-29

Andreae MO, Ferek RJ, Bermond F, Byrd KP, Engstrom RT, Hardin S, Houmere PD, Lemarrec F, Raemdonck H, Chatfield RB (1985) Dimethyl sulfide in the marine atmosphere. J Geophys Res-Atmos 90(D7):2891-2900

Andreae TW, Andreae MO, Schebeske G (1994) Biogenic sulfur emissions and aerosols over the tropical South Atlantic: 1. Dimethylsulfide in sea water and in the atmospheric boundary layer. J Geophys Res-Atmos 99(D11):22819-22829

Andreae MO, Elbert W, Demora SJ (1995) Biogenic sulfur emissions and aerosols over the tropical South- Atlantic. 3. Atmospheric dimethylsulfide, aerosols and cloud condensation nuclei. $\mathrm{J}$ Geophys Res-Atmos 100(D6):11335-11356

Archer SD, Ragni M, Webster R, Airs RL, Geider RJ (2010) Dimethyl sulfoniopropionate and dimethyl sulfide production in response to photoinhibition in Emiliania huxleyi. Limnol Oceanogr 55(4):1579-1589

Ayers GP, Cainey JM (2007) The CLAW hypothesis: a review of the major developments. Environ Chem 4(6):366-374

Bates TS, Charlson RJ, Gammon RH (1987) Evidence for the climatic role of marine biogenic sulphur. Nature 329(6137):319-321

Bates TS, Lamb BK, Guenther A, Dignon J, Stoiber RE (1992) Sulfur emissions to the atmosphere from natural sources. J Atmos Chem 14(1-4):315-337

Bates SC, Fox-Kemper B, Jayne SR, Large WG, Stevenson S, Yeager SG (2012) Mean biases, variability, and trends in air-sea fluxes and sea surface temperature in the CCSM4. J Clim 25(22):7781-7801

Bopp L, Aumont O, Belviso S, Monfray P (2003) Potential impact of climate change on marine dimethyl sulfide emissions. Tellus Ser B-Chem Phys Meteorol 55(1):11-22

Bopp L, Boucher O, Aumont O, Belviso S, Dufresne JL, Pham M, Monfray P (2004) Will marine dimethylsulfide emissions amplify or alleviate global warming? A model study. Can J Fish Aquat Sci 61(5):826-835 
Bopp L, Aumont O, Belviso S, Blain S (2008) Modelling the effect of iron fertilization on dimethylsulphide emissions in the Southern Ocean. Deep-Sea Res Part Ii-Top Stud Oceanogr 55(5-7):901-912

Browse J, Carslaw KS, Mann GW, Birch CE, Arnold SR, Leck C (2014) The complex response of Arctic aerosol to sea-ice retreat. Atmos Chem Phys 14(14):7543-7557

Buitenhuis E, Le Quere C, Aumont O, Beaugrand G, Bunker A, Hirst A, Ikeda T, O'Brien T, Piontkovski S, Straile D (2006) Biogeochemical fluxes through mesozooplankton. Glob Biogeochem Cycles 20(2):GB2003

Cameron-Smith P, Lamarque JF, Connell P, Chuang C, Vitt F (2006) Toward an Earth system model: atmospheric chemistry, coupling, and petascale computing. J Phys 46:343-350

Cameron-Smith P, Elliott S, Maltrud M, Erickson D, Wingenter $\mathrm{O}$ (2011) Changes in dimethyl sulfide oceanic distribution due to climate change. Geophys Res Lett 38:L07704

Carslaw KS, Boucher O, Spracklen DV, Mann GW, Rae JGL, Woodward S, Kulmala M (2010) A review of natural aerosol interactions and feedbacks within the Earth system. Atmos Chem Phys 10(4):1701-1737

Charlson RJ, Lovelock JE, Andreae MO, Warren SG (1987) Oceanic phytoplankton, atmospheric sulphur, cloud albedo and climate. Nature 326(6114):655-661

Chin M, Jacob DJ (1996) Anthropogenic and natural contributions to tropospheric sulfate: a global model analysis. J Geophys Res-Atmos 101(D13):18691-18699

Danabasoglu G, Bates SC, Briegleb BP, Jayne SR, Jochum M, Large WG, Peacock S, Yeager SG (2012) The CCSM4 ocean component. J Clim 25(5):1361-1389

Derevianko GJ, Deutsch C, Hall A (2009) On the relationship between ocean DMS and solar radiation. Geophys Res Lett 36:L17606

Elliott S (2009) Dependence of DMS global sea-air flux distribution on transfer velocity and concentration field type. J Geophys Res-Biogeosci 114:G02001

Elliott S, Deal C, Humphries G, Hunke E, Jeffery N, Jin M, Levasseur M, Stefels J (2012) Pan-Arctic simulation of coupled nutrient-sulfur cycling due to sea ice biology: preliminary results. J Geophys Res-Biogeosci 117:G01016

Flombaum P, Gallegos JL, Gordillo RA, Rincon J, Zabala LL, Jiao N, Karl DM, Li WKW, Lomas MW, Veneziano D, Vera CS, Vrugt JA, Martiny AC (2013) Present and future global distributions of the marine Cyanobacteria Prochlorococcus and Synechococcus. Proc Natl Acad Sci USA 110(24):9824-9829

Gabric AJ, Whetton PH, Boers R, Ayers GP (1998) The impact of simulated climate change on the air-sea flux of dimethylsulphide in the subantarctic Southern Ocean. Tellus Ser B-Chem Phys Meteorol 50(4):388-399

Gabric AJ, Whetton PH, Cropp R (2001) Dimethylsulphide production in the subantarctic southern ocean under enhanced greenhouse conditions. Tellus Ser B-Chem Phys Meteorol 53(3):273-287

Gabric AJ, Simo R, Cropp RA, Hirst AC, Dachs J (2004) Modeling estimates of the global emission of dimethylsulfide under enhanced greenhouse conditions. Glob Biogeochem Cycles 18(2):GB2014

Gabric AJ, Qu B, Rotstayn L, Shephard JM (2013) Global simulations of the impact on contemporary climate of a perturbation to the sea-to-air flux of dimethylsulfide. Aust Meteorol Oceanogr J 63(3):365-376

Gent PR, Danabasoglu G, Donner LJ, Holland MM, Hunke EC, Jayne SR, Lawrence DM, Neale RB, Rasch PJ, Vertenstein M, Worley PH, Yang Z-L, Zhang M (2011) The community climate system model version 4. J Clim 24(19):4973-4991

Gettelman A, Morrison H, Ghan SJ (2008) A new two-moment bulk stratiform cloud microphysics scheme in the Community Atmosphere Model, version 3 (CAM3). Part II: single-column and global results. J Clim 21(15):3660-3679

Gondwe M, Krol M, Gieskes W, Klaassen W, de Baar H (2003) The contribution of ocean-leaving DMS to the global atmospheric burdens of DMS, MSA, $\mathrm{SO}_{2}$, and $\mathrm{NSS} \mathrm{SO}_{4}^{=}$. Glob Biogeochem Cycles 17(2):1056

Green TK, Hatton AD (2014) The claw hypothesis: a new perspective on the role of biogenic sulphur in the regulation of global climate. Oceanogr Mar Biol 52(52):315-335

Griffies SM, Winton M, Samuels B, Danabasoglu G, Yeager S, Marsland S, Drange H, Bentsen M (2012) Datasets and protocol for the CLIVAR WGOMD coordinated ocean seaice reference experiments (COREs). WCRP, Report No. 21/2012, p 21

Gunson JR, Spall SA, Anderson TR, Jones A, Totterdell IJ, Woodage MJ (2006) Climate sensitivity to ocean dimethylsulphide emissions. Geophys Res Lett 33(7):L07701

Halloran PR, Bell TG, Totterdell IJ (2010) Can we trust empirical marine DMS parameterisations within projections of future climate? Biogeosciences 7(5):1645-1656

Hunke EC, Lipscomb WH (2010), CICE: the Los Alamos Sea Ice Model Documentation and Software User's Manual Version 4.1, LA-CC-06-012, T-3 Fluid Dynamics Group, Los Alamos National Laboratory, Los Alamos, NM

Hurrell JW, Holland MM, Gent PR, Ghan S, Kay JE, Kushner PJ, Lamarque JF, Large WG, Lawrence D, Lindsay K, Lipscomb WH, Long MC, Mahowald N, Marsh DR, Neale RB, Rasch P, Vavrus S, Vertenstein M, Bader D, Collins WD, Hack JJ, Kiehl J, Marshall S (2013) The community earth system model a framework for collaborative research. Bull Am Meteorol Soc 94(9):1339-1360

Jones A, Roberts DL, Woodage MJ, Johnson CE (2001) Indirect sulphate aerosol forcing in a climate model with an interactive sulphur cycle. J Geophys Res-Atmos 106(D17):20293-20310

Kalnay E, Kanamitsu M, Kistler R, Collins W, Deaven D, Gandin L, Iredell M, Saha S, White G, Woollen J, Zhu Y, Chelliah M, Ebisuzaki W, Higgins W, Janowiak J, Mo KC, Ropelewski C, Wang J, Leetmaa A, Reynolds R, Jenne R, Joseph D (1996) The NCEP/NCAR 40-year reanalysis project. Bull Am Meteorol Soc 77(3):437-471

Karsten U, Wiencke C, Kirst GO (1992) Dimethylsulphoniopropionate (DMSP) accumulation in green macioalgae from polar to temperate regions: interactive effects of light versus salinity and light versus temperature. Polar Biol 12(6-7):603-607

Keller MD, Korjeff-Bellows W (1996) Physiological aspects of the production of dimethylsulfoniopropionate (DMSP) by marine phytoplankton. In: Biological and Environmental 
Chemistry of Dmsp and Related Sulfonium Compounds. Springer, Boston, pp 131-142

Keller MD, Bellows WK, Guillard RRL (1989) Dimethyl sulfide production in marine phytoplankton. ACS Symp Ser 393:167-182

Kettle AJ, Andreae MO, Amouroux D, Andreae TW, Bates TS, Berresheim H, Bingemer H, Boniforti R, Curran MAJ, DiTullio GR, Helas G, Jones GB, Keller MD, Kiene RP, Leck C, Levasseur M, Malin G, Maspero M, Matrai P, McTaggart AR, Mihalopoulos N, Nguyen BC, Novo A, Putaud JP, Rapsomanikis S, Roberts G, Schebeske G, Sharma S, Simo R, Staubes R, Turner S, Uher G (1999) A global database of sea surface dimethylsulfide (DMS) measurements and a procedure to predict sea surface DMS as a function of latitude, longitude, and month. Glob Biogeochem Cycles 13(2):399-444

Kiene RP, Linn LJ, Bruton JA (2000) New and important roles for DMSP in marine microbial communities. J Sea Res 43(3-4):209-224

Kloster S, Six KD, Feichter J, Maier-Reimer E, Roeckner E, Wetzel P, Stier P, Esch M (2007) Response of dimethylsulfide (DMS) in the ocean and atmosphere to global warming. J Geophys Res-Biogeosci 112(G3):G03005

Lamarque JF, Emmons LK, Hess PG, Kinnison DE, Tilmes S, Vitt F, Heald CL, Holland EA, Lauritzen PH, Neu J, Orlando JJ, Rasch PJ, Tyndall GK (2012) CAM-chem: description and evaluation of interactive atmospheric chemistry in the Community Earth System Model. Geosci Model Dev 5(2):369-411

Lana A, Bell TG, Simo R, Vallina SM, Ballabrera-Poy J, Kettle AJ, Dachs J, Bopp L, Saltzman ES, Stefels J, Johnson JE, Liss PS (2011) An updated climatology of surface dimethlysulfide concentrations and emission fluxes in the global ocean. Glob Biogeochem Cycles 25:GB1004

Large WG, Yeager SG (2009) The global climatology of an interannually varying air-sea flux data set. Clim Dyn 33(2-3):341-364

Lawrence DM, Oleson KW, Flanner MG, Thornton PE, Swenson SC, Lawrence PJ, Zeng X, Yang Z-L, Levis S, Sakaguchi K, Bonan GB, Slater AG (2011) Parameterization improvements and functional and structural advances in version 4 of the Community Land Model. J Adv Model Earth Syst 3:M03001

Le Clainche Y, Levasseur M, Vezina A, Dacey JWH, Saucier FJ (2004) Behaviour of the ocean DMS(P) pools in the Sargasso Sea viewed in a coupled physical-biogeochemical ocean model. Can J Fish Aquat Sci 61(5):788-803

Leck C, Larsson U, Bagander LE, Johansson S, Hajdu S (1990) Dimethyl sulfide in the Baltic Sea: annual variability in relation to biological activity. J Geophys Res-Oceans 95(C3):3353-3363

Lindsay K, Bonan GB, Doney SC, Hoffman FM, Lawrence DM, Long MC, Mahowald NM, Moore JK, Randerson JT, Thornton PE (2014) Preindustrial-control and twentiethcentury carbon cycle experiments with the earth system model CESM1(BGC). J Clim 27(24):8981-9005

Liu X, Easter RC, Ghan SJ, Zaveri R, Rasch P, Shi X, Lamarque JF, Gettelman A, Morrison H, Vitt F, Conley A, Park S, Neale R, Hannay C, Ekman AML, Hess P, Mahowald N, Collins W, Iacono MJ, Bretherton CS, Flanner MG, Mitchell D (2012) Toward a minimal representation of aerosols in climate models: description and evaluation in the Community Atmosphere Model CAM5. Geosci Model Dev 5(3):709-739

Long MC, Lindsay K, Peacock S, Moore JK, Doney SC (2013) Twentieth-century oceanic carbon uptake and storage in CESM1(BGC). J Clim 26(18):6775-6800

Lovelock JE, Maggs RJ, Rasmusse RA (1972) Atmospheric dimethyl sulphide and the natural sulphur cycle. Nature 237(5356):452-453

Moore JK, Braucher O (2008) Sedimentary and mineral dust sources of dissolved iron to the world ocean. Biogeosciences 5(3):631-656

Moore JK, Doney SC, Kleypas JA, Glover DM, Fung IY (2002) An intermediate complexity marine ecosystem model for the global domain. Deep-Sea Res Part Ii-Top Stud Oceanogr 49(1-3):403-462

Moore JK, Doney SC, Lindsay K (2004) Upper ocean ecosystem dynamics and iron cycling in a global three-dimensional model. Glob Biogeochem Cycles 18(4):GB4028

Moore JK, Lindsay K, Doney SC, Long MC, Misumi K (2013) Marine ecosystem dynamics and biogeochemical cycling in the community Earth system model CESM1(BGC): comparison of the $1990 \mathrm{~s}$ with the $2090 \mathrm{~s}$ under the RCP4.5 and RCP8.5 scenarios. J Clim 26(23):9291-9312

Morrison H, Gettelman A (2008) A new two-moment bulk strati- form cloud microphysics scheme in the community atmosphere model, version 3 (CAM3). Part I: description and numerical tests. J Clim 21(15):3642-3659

Neale RB, Coauthors (2010) Description of the NCAR Community Atmosphere Model (CAM5.0). NCAR Tech Rep NCAR/TN-486+STR, 268 pp

Park S, Bretherton CS, Rasch PJ (2014) Integrating cloud processes in the community atmosphere model, version 5 . J Clim 27(18):6821-6856

Quinn PK, Bates TS (2011) The case against climate regulation via oceanic phytoplankton sulphur emissions. Nature 480(7375):51-56

Sharma S, Chan E, Ishizawa M, Toom-Sauntry D, Gong SL, Li SM, Tarasick DW, Leaitch WR, Norman A, Quinn PK, Bates TS, Levasseur M, Barrie LA, Maenhaut W (2012) Influence of transport and ocean ice extent on biogenic aerosol sulfur in the Arctic atmosphere. J Geophys ResAtmos 117:D12209

Six KD, Maier-Reimer E (2006) What controls the oceanic dimethylsulfide (DMS) cycle? A modeling approach. Glob Biogeochem Cycles 20(4):GB4011

Six KD, Kloster S, Ilyina T, Archer SD, Zhang K, Maier-Reimer E (2013) Global warming amplified by reduced sulphur fluxes as a result of ocean acidification. Nat Clim Change 3(11):975-978

Smith RD, Jones P, Briegleb B, Bryan F, Danabasoglu G, Dennis J, Dukowicz J, Eden C, Fox-Kemper B, Gent P, Hecht M, Jayne S, Jochum M, Large W, Lindsay K, Maltrud M, Norton N, Peacock S, Vertenstein M, Yeager S (2010) The parallel ocean program (POP) reference manual: ocean component of the community climate system model (CCSM) and community earth system model (CESM). Los Alamos National Laboratory Tech. Rep. LAUR-10-01853, Los Alamos, NM, p 141 
Stefels J (2000) Physiological aspects of the production and conversion of DMSP in marine algae and higher plants. J Sea Res 43(3-4):183-197

Stefels J, Steinke M, Turner S, Malin G, Belviso S (2007) Environmental constraints on the production and removal of the climatically active gas dimethylsulphide (DMS) and implications for ecosystem modelling. Biogeochemistry 83(1-3):245-275

Sunda W, Kieber DJ, Kiene RP, Huntsman S (2002) An antioxidant function for DMSP and DMS in marine algae. Nature 418(6895):317-320

Sunda WG, Hardison R, Kiene RP, Bucciarelli E, Harada H (2007) The effect of nitrogen limitation on cellular DMSP and DMS release in marine phytoplankton: climate feedback implications. Aquat Sci 69(3):341-351

Thomas MA, Suntharalingam P, Pozzoli L, Rast S, Devasthale A, Kloster S, Feichter J, Lenton TM (2010) Quantification of DMS aerosol-cloud-climate interactions using the ECHAM5-HAMMOZ model in a current climate scenario. Atmos Chem Phys 10(15):7425-7438

Tilmes S, Lamarque JF, Emmons LK, Kinnison DE, Ma PL, Liu X, Ghan S, Bardeen C, Arnold S, Deeter M, Vitt F, Ryerson T, Elkins JW, Moore F, Spackman JR, Martin MV (2015) Description and evaluation of tropospheric chemistry and aerosols in the Community Earth System Model (CESM1.2). Geosci Model Dev 8(5):1395-1426

Trevena A, Jones G (2012) DMS flux over the Antarctic sea ice zone. Mar Chem 134:47-58

Vallina SM, Simo R, Manizza M (2007) Weak response of oceanic dimethylsulfide to upper mixing shoaling induced by global warming. Proc Natl Acad Sci USA 104(41):16004-16009 van Rijssel M, Gieskes WWC (2002) Temperature, light, and the dimethylsulfoniopropionate (DMSP) content of Emiliania huxleyi (Prymnesiophyceae). J Sea Res 48(1):17-27

Vogt M, Vallina SM, Buitenhuis ET, Bopp L, Le Quere C (2010) Simulating dimethylsulphide seasonality with the dynamic green ocean model PlankTOM5. J Geophys ResOceans 115:C06021

Wang S, Moore JK (2011) Incorporating Phaeocystis into a Southern Ocean ecosystem model. J Geophys Res-Oceans 116:C01019

Wang S, Moore JK, Primeau FW, Khatiwala S (2012) Simulation of anthropogenic CO2 uptake in the CCSM3.1 ocean circulation-biogeochemical model: comparison with databased estimates. Biogeosciences 9(4):1321-1336

Wang S, Elliott S, Maltrud M, Cameron-Smith P (2015) Influence of explicit Phaeocystis parameterizations on the global distribution of marine dimethyl sulfide. J Geophys ResBiogeosci 120(11):2158-2177

Wolfe GV, Steinke M (1996) Grazing-activated production of dimethyl sulfide (DMS) by two clones of Emiliania huxleyi. Limnol Oceanogr 41(6): 1151-1160

Woodhouse MT, Carslaw KS, Mann GW, Vallina SM, Vogt M, Halloran PR, Boucher O (2010) Low sensitivity of cloud condensation nuclei to changes in the sea-air flux of dimethyl-sulphide. Atmos Chem Phys 10(16):7545-7559

Woodhouse MT, Mann GW, Carslaw KS, Boucher O (2013) Sensitivity of cloud condensation nuclei to regional changes in dimethyl-sulphide emissions. Atmos Chem Phys 13(5):2723-2733

Zemmelink HJ, Dacey JWH, Houghton L, Hintsa EJ, Liss PS (2008) Dimethylsulfide emissions over the multi-year ice of the western Weddell Sea. Geophys Res Lett 35(6):L06603 